\title{
CAMA
}

Centre for Applied Macroeconomic Analysis

\section{Zero Lower Bound and Parameter Bias in an Estimated DSGE Model}

\section{CAMA Working Paper 60/2013 September 2013}

\author{
Yasuo Hirose \\ Faculty of Economics, Keio University and \\ Centre for Applied Macroeconomic Analysis (CAMA), ANU \\ Atsushi Inoue \\ Department of Economics, Southern Methodist University
}

\begin{abstract}
This paper examines how and to what extent parameter estimates can be biased in a dynamic stochastic general equilibrium (DSGE) model that omits the zero lower bound constraint on the nominal interest rate. Our experiments show that most of the parameter estimates in a standard sticky-price DSGE model are not biased although some biases are detected in the estimates of the monetary policy parameters and the steady-state real interest rate. Nevertheless, in our baseline experiment, these biases are so small that the estimated impulse response functions are quite similar to the true impulse response functions. However, as the probability of hitting the zero lower bound increases, the biases in the parameter estimates become larger and can therefore lead to substantial differences between the estimated and true impulse responses.
\end{abstract}




\section{Keywords}

Zero lower bound, DSGE model, Parameter bias, Bayesian estimation

\section{JEL Classification}

C32, E30, E52

\section{Address for correspondence:}

(E) cama.admin@anu.edu.au

The Centre for Applied Macroeconomic Analysis in the Crawford School of Public Policy has been established to build strong links between professional macroeconomists. It provides a forum for quality macroeconomic research and discussion of policy issues between academia, government and the private sector.

The Crawford School of Public Policy is the Australian National University's public policy school, serving and influencing Australia, Asia and the Pacific through advanced policy research, graduate and executive education, and policy impact. 


\title{
Zero Lower Bound and Parameter Bias in an Estimated DSGE Model*
}

\author{
Yasuo Hirose $^{\dagger} \quad$ Atsushi Inoue ${ }^{\ddagger}$
}

September 2013

\begin{abstract}
This paper examines how and to what extent parameter estimates can be biased in a dynamic stochastic general equilibrium (DSGE) model that omits the zero lower bound constraint on the nominal interest rate. Our experiments show that most of the parameter estimates in a standard sticky-price DSGE model are not biased although some biases are detected in the estimates of the monetary policy parameters and the steady-state real interest rate. Nevertheless, in our baseline experiment, these biases are so small that the estimated impulse response functions are quite similar to the true impulse response functions. However, as the probability of hitting the zero lower bound increases, the biases in the parameter estimates become larger and can therefore lead to substantial differences between the estimated and true impulse responses.
\end{abstract}

Keywords: Zero lower bound, DSGE model, Parameter bias, Bayesian estimation JEL Classification: C32, E30, E52

${ }^{*}$ We would like to thank Xiaoshan Chen, Günter Coenen, Andrew Foerster, Nikolay Iskrev, Fabio Milani, Tatevik Sekhposyan, and participants at the International Conference on Computing in Economics and Finance and the North American Summer Meeting of the Econometric Society for insightful comments and discussions.

${ }^{\dagger}$ Faculty of Economics, Keio University and Centre for Applied Macroeconomic Analysis, Australian National University. E-mail: yhirose@econ.keio.ac.jp

${ }^{\ddagger}$ Department of Economics, Southern Methodist University. E-mail: ainoue@mail.smu.edu 


\section{Introduction}

Dynamic stochastic general equilibrium (DSGE) models have become a prominent tool for policy analysis. In particular, following the development of Bayesian estimation and evaluation techniques, estimated DSGE models have been extensively used by a range of policy institutions, including central banks. At the same time, the zero lower bound constraint on the nominal interest rates has been a primary concern for policymakers. Much work has been devoted to understand how the economy works and how policy should be conducted in the presence of this constraint from a theoretical perspective. ${ }^{1}$ However, empirical studies that estimate DSGE models including the interest-rate lower bound are still scarce because of computational difficulties in the treatment of nonlinearity arising from the bound, ${ }^{2}$ and hence most practitioners continue to estimate linearized DSGE models without explicitly considering the lower bound.

This paper examines how and to what extent the estimates of structural parameters can be biased in an estimated DSGE model where the existence of the interest-rate lower bound is omitted in the estimation process. Suppose that there is a zero lower bound constraint in the economy and that an econometrician fits a model without taking into account this constraint. We would then expect the parameter estimates in the model to be biased. If significant biases were detected, it would cast some doubt on the common practice in which the zero lower bound constraint is not explicitly taken into account and would motivate researchers toward the use of an estimation procedure that deals with the constraint. Conversely, if the biases involved are negligible, it would at least assure practitioners that their common practice leads to reliable estimates in its own way.

More specifically, we construct artificial time series simulated from a standard sticky-price DSGE model that incorporates an occasionally binding constraint on the nominal interest rate.

\footnotetext{
${ }^{1}$ See, for instance, Eggertsson and Woodford (2003), Jung, Teranishi, and Watanabe (2005), Adam and Billi (2006, 2007), Christiano, Eichenbaum, and Rebelo (2011), Aruoba and Schorfheide (2013), Bodenstein, Guerrieri, and Gust (2013), Braun, Körber, and Waki (2012), Erceg and Lindé (2012), Fernández-Villaverde, Gordon, Guerrón-Quintana, and Rubio-Ramírez (2012), and Gavin, Keen, Richter, and Throckmorton (2013).

${ }^{2}$ A remarkable exception is Gust, López-Salido, and Smith (2012) who estimate a nonlinear DSGE model in which the interest-rate lower bound is occasionally binding. Based on the estimated model, they quantify the effect of the zero lower bound constraint on the recent economic slump in the US.
} 
The parameters calibrated in this data generating process (DGP) are regarded as true values. The solution algorithm follows from Erceg and Lindé (2012) and Bodenstein, Guerrieri, and Gust (2013). ${ }^{3}$ In their algorithm, if the model-implied nominal interest rate falls below zero, a sequence of contractionary monetary policy shocks is added in both the current and anticipated periods so that the contemporaneous and expected interest rates at the lower bound are zero. Then, using the simulated data, the model is estimated without including the interest-rate lower bound. In the estimation, we employ Bayesian methods, which are now extensively used to estimate DSGE models. We set the prior means to the true parameter values and assess the parameter biases from neglecting the lower bound by comparing the posterior means and Bayesian credible intervals with the true values.

One could argue that the DGP in our analysis should be replaced with a fully nonlinear model as in Braun, Körber, and Waki (2012), Fernández-Villaverde, Gordon, GuerrónQuintana, and Rubio-Ramírez (2012) or Gust, López-Salido, and Smith (2012). However, if the DGP is characterized by a fully nonlinear model, we cannot identify the source of parameter bias: whether the exclusion of the interest-rate lower bound or the linearization of the model. In this regard, the solution method employed in this paper is compatible with the standard solution algorithms for linear rational expectations models, such as Blanchard and Kahn (1980) and Sims (2002). Therefore, our analysis points to parameter bias only resulting from omitting the zero lower bound constraint.

Our main results are summarized as follows. In the baseline economy, where the true value for the steady-state real interest rate is calibrated such that the probability of hitting the zero lower bound is about five percent, we find that most of the parameter estimates are not biased, although some biases are detected in the estimates of the monetary policy parameters and the steady-state real interest rate. We demonstrate that these biases in parameter estimates do not amount to substantial biases in the estimates of the impulse response functions. ${ }^{4}$ However, if the true parameter values in the DGP are altered such that the probability of binding at the constraint increases, we show that the biases in the parameter estimates become larger

\footnotetext{
${ }^{3}$ These studies apply the method in Laséen and Svensson (2011), who propose a convenient algorithm to construct policy projections conditional on alternative anticipated policy rate paths in linearized DSGE models.

${ }^{4}$ Our robustness analysis shows that these results hold even if we use a larger-scale DSGE model à la Smets and Wouters (2003, 2007).
} 
and that the estimated impulse response functions can then substantially differ from the true functions. This finding suggests that researchers in a very low interest rate environment should make use of an estimation procedure that explicitly takes into account the zero lower bound.

The remainder of the paper proceeds as follows. Section 2 describes the stylized DSGE model used for our analysis and the solution algorithm that incorporates the occasionally binding constraint on the nominal interest rate into the linear rational expectations system. Section 3 explains the experimental design used for the analysis and presents our results. Section 4 conducts a robustness analysis with a larger-scale DSGE model. Section 5 is the conclusion.

\section{The Model and Solution Method}

This section describes the DGP used in our analysis. The DGP consists of a small-scale DSGE model with sticky prices and a monetary policy rule. In order to incorporate the zero lower bound constraint on the nominal interest rate, the model is solved using the method employed in Erceg and Lindé (2012) and Bodenstein, Guerrieri, and Gust (2013).

\subsection{The Model}

In the model economy, there are households, perfectly competitive final-good firms, monopolistically competitive intermediate-good firms that face price stickiness, and a monetary authority. For empirical validity, the model features habit persistence in consumption preferences, price indexation to recent past and steady-state inflation, and monetary policy smoothing. A similar model is used in Dennis (2004, 2009) and Milani and Treadwell (2012), among others.

The log-linearized equilibrium conditions are summarized as follows: ${ }^{5}$

$$
\begin{aligned}
\tilde{Y}_{t} & =\frac{1}{1+\gamma} E_{t} \tilde{Y}_{t+1}+\frac{\gamma}{1+\gamma} \tilde{Y}_{t-1}-\frac{1-\gamma}{\sigma(1+\gamma)}\left(\tilde{r}_{t}^{n}-E_{t} \tilde{\pi}_{t+1}\right)+z_{t}^{d}, \\
\tilde{\pi}_{t} & =\frac{\beta}{1+\beta \iota} E_{t} \tilde{\pi}_{t+1}+\frac{\iota}{1+\beta \iota} \tilde{\pi}_{t-1} \\
& +\frac{(1-\xi)(1-\xi \beta)}{\xi(1+\beta \iota)}\left[\left(\chi+\frac{\sigma}{1-\gamma}\right) \tilde{Y}_{t}-\frac{\sigma \gamma}{1-\gamma} \tilde{Y}_{t-1}\right]+z_{t}^{p}, \\
\tilde{r}_{t}^{n} & =\max \left[\phi_{r} \tilde{r}_{t-1}^{n}+\left(1-\phi_{r}\right)\left(\phi_{\pi} \tilde{\pi}_{t}+\phi_{y} \tilde{Y}_{t}\right)+z_{t}^{r},-(\bar{r}+\bar{\pi})\right]
\end{aligned}
$$

\footnotetext{
${ }^{5}$ See the Appendix for the full description of the model.
} 
Eq. (1) is the spending Euler equation, where $\tilde{Y}_{t}, \tilde{r}_{t}^{n}$ and $\tilde{\pi}_{t}$ are output, the nominal interest rate, and inflation in terms of the percentage deviations from their steady-state values, $z_{t}^{d}$ is a shock to households' preferences, interpreted as a demand shock, $\gamma \in[0,1]$ is the degree of habit persistence, and $\sigma>0$ is the inverse of the intertemporal elasticity of substitution.

Eq. (2) is the New Keynesian Phillips curve, where $\beta \in(0,1)$ is the subjective discount factor determined by the steady-state relationship $\beta=\pi / r$, where $\pi$ and $r$ are the steady-state gross inflation and real interest rate respectively, $\iota \in[0,1]$ is the weight of price indexation to recent past inflation $\pi_{t-1}$ relative to steady-state inflation $\pi, \xi \in(0,1)$ is the so called Calvo parameter, which measures the degree of price stickiness, and $\chi>0$ is the inverse of the elasticity of labor supply. $z_{t}^{p}$ is a cost-push shock.

Eq. (3) is a Taylor (1993) type monetary policy rule with the zero lower bound on the nominal interest rate, where $\phi_{r} \in[0,1)$ is the degree of interest rate smoothing, $\phi_{\pi}>1$ and $\phi_{y}>0$ represent the degrees of interest rate policy responses to inflation and output gap respectively, $z_{t}^{r}$ is a monetary policy shock, and $\bar{\pi}=100(\pi-1)$ and $\bar{r}=100(r-1)$ are the steady-state values for the real interest rate and inflation, respectively. As $\tilde{r}_{t}^{n}$ is expressed as the deviation from the steady-state nominal interest rate $\bar{r}+\bar{\pi}$, the max function constrains the level of the nominal interest rate to be greater than or equal to zero.

Each shock $z_{t}^{x}, x \in\{d, p, r\}$ is governed by a stationary first-order autoregressive process:

$$
z_{t}^{x}=\rho_{x} z_{t-1}^{x}+\varepsilon_{t}^{x}
$$

where $\rho_{x} \in[0,1)$ is an autoregressive coefficient and $\varepsilon_{t}^{x}$ is a normally distributed innovation with mean zero and standard deviation $\sigma_{x n}$.

In the DGP, the percentage deviation of output from the steady state $100 \log \left(Y_{t} / Y\right)$, the inflation rate $100 \log \pi_{t}$, and the nominal interest rate $100 \log r_{t}^{n}$ are assumed to be observable. Then, these observables are related to the model-implied variables by the following observation equations:

$$
\left[\begin{array}{c}
100 \log \left(Y_{t} / Y\right) \\
100 \log \pi_{t} \\
100 \log r_{t}^{n}
\end{array}\right]=\left[\begin{array}{c}
0 \\
\bar{\pi} \\
\bar{r}+\bar{\pi}
\end{array}\right]+\left[\begin{array}{c}
\tilde{Y}_{t} \\
\tilde{\pi}_{t} \\
\tilde{r}_{t}^{n}
\end{array}\right]
$$




\section{$2.2 \quad$ Parameter Setting}

The model is parameterized according to standard choices in the literature in order to make our test economy as representative as possible. Table 1 summarizes our baseline parameter setting.

The inverse of intertemporal elasticity of substitution $\sigma$ is set to be unity, so that the households' preferences are characterized by the log-utility function. We assign the inverse of the elasticity of labor supply $\chi=1$. The habit persistence and price indexation parameters, $\gamma$ and $\iota$, are both set at 0.5. As is often the case in the New Keynesian literature, we set the Calvo parameter $\xi=0.75$, which implies that the average duration of prices is four quarters. The monetary policy parameters $\left(\phi_{\pi}=1.5, \phi_{y}=0.125\right)$ that represent the degrees of interest rate responses to inflation and output gap follow from the coefficients in the original Taylor (1993) rule, adapted to a quarterly frequency. The policy-smoothing parameter $\phi_{r}$ is set to be 0.5. The steady-state inflation rate $\bar{\pi}$ is set at 0.5 , implying that the central bank's target inflation rate is two percent annually. The steady-state value of the real interest rate $(\bar{r}=0.5)$ is almost the same as the average of the ex-post real interest rate calculated from the three-month Treasury bill rate and changes in the GDP implicit deflator in the post-1980s US sample.

For each shock, moderate persistency is assumed: $\rho_{d}=0.5, \rho_{p}=0.5, \rho_{r}=0.5$. The standard deviation of each shock $\left(\sigma_{d}=0.25, \sigma_{p}=0.25, \sigma_{r}=0.25\right)$ is calibrated in line with the prior mean often used in the literature that estimate similar DSGE models using Bayesian methods.

\subsection{Solution Method}

The solution algorithm follows from Erceg and Lindé (2012) and Bodenstein, Guerrieri, and Gust (2012). They apply the method in Laséen and Svensson (2011), who propose a convenient algorithm to construct policy projections conditional on alternative anticipated policy rate paths in linearized DSGE models. This solution method is compatible with the standard solution algorithms for linear rational expectations models, such as Blanchard and Kahn (1980) and Sims (2002), and hence yields a straightforward interpretation about the implications of the zero bound constraint. 
To be specific, Eq. (3) that includes the max operator is replaced with:

$$
\tilde{r}_{t}^{n}=\phi_{r} \tilde{r}_{t-1}^{n}+\left(1-\phi_{r}\right)\left(\phi_{\pi} \tilde{\pi}_{t}+\phi_{y} \tilde{Y}_{t}\right)+z_{t}^{r}+m_{t}
$$

where $m_{t}$ is the contractionary monetary policy shock that enforces the zero lower bound constraint. If the unconstrained nominal interest rate $\bar{r}+\bar{\pi}+\phi_{r} \tilde{r}_{t-1}^{n}+\left(1-\phi_{r}\right)\left(\phi_{\pi} \tilde{\pi}_{t}+\phi_{y} \tilde{Y}_{t}\right)+z_{t}^{r}$ (in terms of percentage level) falls below zero, a positive $m_{t}$ is endogenously determined so that $\bar{r}+\bar{\pi}+\phi_{r} \tilde{r}_{t-1}^{n}+\left(1-\phi_{r}\right)\left(\phi_{\pi} \tilde{\pi}_{t}+\phi_{y} \tilde{Y}_{t}\right)+z_{t}^{r}+m_{t}=0$. We call this $m_{t}$ a binding shock.

$m_{t}$ should be treated not only as an unanticipated shock but also as an anticipated shock given agents facing large negative shocks in the economy expect that the nominal interest rate should be at the zero lower bound for some periods in the future. To take such expectation channel into account, $m_{t}$ is extended as follows:

$$
\begin{aligned}
m_{t} & =m_{t-1}^{1}+\nu_{t}^{0} \\
m_{t}^{1} & =m_{t-1}^{2}+\nu_{t}^{1} \\
m_{t}^{2} & =m_{t-1}^{3}+\nu_{t}^{2} \\
\vdots & \\
m_{t}^{K-1} & =m_{t-1}^{K}+\nu_{t}^{K-1} \\
m_{t}^{K} & =\nu_{t}^{K},
\end{aligned}
$$

where $K$ is the maximum number of future periods in which the unconstrained monetary policy rule implies the negative nominal interest rate. Based on this specification of the binding shock, each $\nu_{t}^{k}, k=0,1, \ldots, K$ has an effect on $E_{t} \tilde{r}_{t+k}^{n}$ since $E_{t} m_{t+k}=\nu_{t}^{k}$. Therefore, if $\bar{r}+\bar{\pi}+E_{t} \tilde{r}_{t+k}^{n}<0$ without the binding shocks, $\bar{r}+\bar{\pi}+E_{t} \tilde{r}_{t+k}^{n}=0$ can be enforced by adjusting $\nu_{t}^{k}$. As these binding shocks are chosen depending on the state of the economy, the expected duration of zero lower bound periods is endogenously determined. In practice, $\nu_{t}^{k}$ affects $E_{t} \tilde{r}_{t+k^{\prime}}^{n}$ for $k^{\prime} \neq k$ because of the dynamic structure of the model, but we can exactly find a set of $\nu_{t}^{k}$ for $k=0,1, \ldots, K$ that ensures the zero lower bound since there are as many binding shocks as there are periods for the zero nominal interest rate.

\section{Econometric Experiments}

In this section, we conduct econometric experiments to examine how the parameter estimates can be biased if the existence of the interest-rate lower bound is excluded in the estimation 
process. Moreover, we investigate the effects of these parameter biases on the model properties by comparing the estimated impulse responses with those based on the true parameter values.

\subsection{Design}

Our experiments proceed as follows. First, we generate an artificial time series of output (deviation from the steady state), inflation, and the nominal interest rate from the DGP as described in the preceding section. Thus, the simulated series can be regarded as those that reflect the existence of the zero lower bound constraint. The simulated sample size is 200 observations, which corresponds to quarterly observations over a period of 50 years. This sample size is chosen because it is comparable to that with which many researchers estimate DSGE models in practice. According to a simulated sample using the baseline parameter setting presented in Table 1, our model economy is at the zero lower bound for 5.5 percent of quarters (11 periods of 200). This probability of hitting the interest-rate lower bound is almost identical to that simulated in Fernández-Villaverde, Gordon, Guerrón-Quintana, and Rubio-Ramírez (2012).

Next, using the simulated data, we estimate the DSGE model that consists of Eq. (1)-(4) together with the observation equations (5) without imposing the zero lower bound on the nominal interest rate. In the estimation, we employ Bayesian methods. The prior distributions of the model parameters are given in Table 2. As each prior mean is set to the corresponding true parameter value used in generating the data, we can evaluate the parameter bias from missing the lower bound constraint by examining how the resulting posterior mean and Bayesian credible interval differ from the true value. To obtain the posterior distributions, we generate 500,000 draws using the random-walk Metropolis-Hastings algorithm and discard the first half of these draws. ${ }^{6}$

\subsection{Results for Baseline Experiment}

The second to fourth columns in Table 3 compare the true parameter values with the posterior means and the 90 percent credible intervals for the estimated parameters in the baseline

\footnotetext{
${ }^{6}$ The scale factor for the jumping distribution in the Metropolis-Hastings algorithm is adjusted so that the acceptance rate of candidate draws is approximately 25 percent. We use the Brooks and Gelman (1998) measure to confirm the convergence of the posterior distributions.
} 
experiment. We can see that most of the estimated parameters are not biased as the posterior mean estimates are very close to the true parameter values and the 90 percent credible intervals contain the true values. This may be good news for many researchers in that the structural parameters relating to preferences and nominal rigidities, the so-called deep parameters, are not much affected by ignoring the interest-rate lower bound. However, we do detect some biases in the estimates of parameters that characterize the monetary policy rule, $\phi_{\pi}$ and $\phi_{r}$, and the steady-state real interest rate $\bar{r}$ in the sense that the credible intervals for these parameters do not include the true values.

An intuitive explanation for these biased estimates is the following. In the DGP, the monetary policy reaction function has a kink where the interest-rate lower bound becomes binding, that is, the reaction function has positive slopes with respect to inflation, output, and the lagged nominal interest rate if the unconstrained nominal interest rate is positive, but the slopes become flat if it is negative. However, when such a kink is omitted in the estimation process, as is the case in our experiment, the estimated slopes are approximated to lie between the positive and flat slopes in the DGP, and thus the parameters in the monetary policy rule can be underestimated. In our experiment, the biases emerge as a change in the estimate of $\phi_{\pi}$ and $\phi_{r}$, although the estimate of $\phi_{y}$ could also be potentially affected. The reason for the upward bias in the estimate of $\bar{r}$ is also straightforward. The presence of the interest-rate lower bound forces the nominal interest rate to be equal or greater than zero. However, if the model estimation fails to consider the zero lower bound, the nominal interest rate can be negative, and the mean of the model-implied nominal interest rate declines. Then, the estimate of the steady-state nominal interest rate must rise to adjust the difference between the mean of the model-implied nominal interest rate and that of the corresponding series simulated from the DGP with the lower bound, given the model is log-linearized around the steady state. In this experiment, such an adjustment has mostly emerged as a change in the estimate of $\bar{r},{ }^{7}$ rather than $\bar{\pi}$. These causes of the parameter biases could have some influence on the estimates of the other structural parameters that characterize the Euler equation and the Phillips curve as we apply the system-based estimation approach. However, our experiment has revealed that such influence is quite limited.

\footnotetext{
${ }^{7}$ A change in $\bar{r}$ affects the subjective discount factor $\beta$ through the steady-state relationship $\beta=\pi / r$ and the definition $r=\bar{r} / 100+1$, but the resulting change in $\beta$ is quite marginal in its magnitude.
} 
Our baseline experiment is based on the posterior estimates for a sample of 200 observations. We cannot deny the possibility that the parameter biases described above may arise because of the small sample, and that sampling variability could lead to different biases, regardless of the exclusion of the interest-rate lower bound. To mitigate the effect of small sample bias, we conduct an experiment using a large sample of 5,000 observations generated from the same DGP. The estimation results are presented in the last two columns in Table 3. As in the baseline experiment, significant biases are found in the estimates of the monetary policy parameters, $\phi_{\pi}$ and $\phi_{r}$, and the steady-state real interest rate $\bar{r}$, and the credible intervals for these parameters do not contain the true values. The other structural parameters are not much biased in that the posterior mean estimates are quite similar to the true parameter values. ${ }^{8}$ Therefore, the baseline results are not altered in this experiment.

An important issue is whether the parameter biases detected in the present experiment can lead to a sizeable difference in the implications of the model. To investigate this issue, we compare the impulse response functions estimated without considering the interest-rate lower bound with those computed using the true parameter values. Figure 1 depicts the impulse responses of output, inflation, and the nominal interest rate to one standard deviation shocks in demand, cost-push, and monetary policy. The responses are expressed in terms of the percentage deviation from the steady state in order to focus on the changes in the transmission of shocks. ${ }^{9}$ In each panel, the solid thick line represents the true response, and the solid thin line and dashed lines are respectively the posterior mean and 90 percent credible interval for the estimated response. Throughout the figure, although small differences are found between the mean estimates and the true response, all the credible intervals include the true responses. Therefore, we can conclude that the parameter biases in the baseline experiment do not amount to substantial biases in the impulse response functions.

\footnotetext{
${ }^{8}$ The credible intervals for some of the parameters do not include their true values, but the mean estimates themselves are not much different from the true values. Thus, we do not assess that these parameter estimates are significantly biased in this experiment.

${ }^{9}$ The estimated responses of the nominal interest rates in level terms are obviously different from the true responses as the estimate of the steady-state real interest rate is biased.
} 


\subsection{Results for Alternative Experiments}

According to the simulated time series in our baseline experiment, the nominal interest rate is bounded at zero for 5.5 percent of quarters. As the probability of hitting the zero lower bound increases in the DGP, it could be possible that parameter biases from excluding the bound in the estimation become large. To analyze such a possibility, we change the parameters assigned to the DGP so that the model economy is more frequently constrained by the interestrate lower bound. We then conduct the same estimation exercises as the baseline experiment using the data simulated by the DGP with the alternative parameter settings. Specifically, we consider two cases. One is where the true steady-state real interest rate falls by 0.25 (one percent annually) so that $\bar{r}=0.25$. The other is where the standard deviation of the demand shock increases to twice its size so that $\sigma_{d}=0.5$. The latter case increases the number of zero interest rate periods because large negative shocks are more likely to depress the economy and to lower the nominal interest rate. In both cases, the probability of hitting the lower bound doubles, that is, they are now 11 percent of the simulated sample.

The middle two columns in Table 4 present the posterior means and the 90 percent credible intervals for the parameters in the experiment where the true parameter value for the real interest rate decreases to $\bar{r}=0.25$. As is the case with the baseline experiment, the estimates of the monetary policy parameter $\phi_{\pi}$ and the steady-state real interest rate $\bar{r}$ exhibit substantial biases. In contrast, the posterior mean estimate of the policy smoothing parameter $\phi_{r}$ is almost the same as the true value. Instead, significant biases are found in the autoregressive coefficient $\rho_{r}$ and the standard deviation $\sigma_{r}$ of the monetary policy shock. However, the other estimates are not very biased in the sense that the posterior credible intervals include their corresponding true values. Figure 2 graphs the estimated and true impulse responses in order to examine the effects of these parameter biases on the model properties. Compared with the responses in the baseline experiment, the differences between the mean estimates and the true responses become large in most of the panels. In particular, the credible intervals for the output responses to the cost-push and monetary policy shocks and the inflation response to the monetary policy shock do not contain the true responses in the first five periods.

The last two columns in Table 4 provide the posterior means and 90 percent credible intervals for the parameters in the experiment where the true standard deviation of the demand shock increases to $\sigma_{d}=0.5$. The estimates of the monetary policy parameters, $\phi_{\pi}$ and $\phi_{r}$, and 
the steady-state real interest rate $\bar{r}$ exhibit larger biases than those in the baseline experiment. In addition, significant biases are found in $\phi_{y}, \rho_{r}$ and $\sigma_{r}$, which are all related to monetary policy, and the credible intervals for these parameters do not include the true values. As in the previous experiment, the estimates of the other parameter estimates are not very biased. According to the impulse responses presented in Figure 3, the true responses are outside the credible intervals in the first few periods regarding the response of the nominal interest rate to the demand shock and the responses of output and inflation to the cost-push shock.

On the basis of the two experiments above, the parameters estimated without considering the zero lower bound constraint may not be sufficiently accurate to replicate the true economic dynamics.

\section{Robustness Analysis}

While we have employed a small-scale DSGE model in our analysis, an increased number of policy institutions are actively developing and estimating larger-scale DSGE models à la Smets and Wouters $(2003,2007)$. Thus, as a robustness analysis, we conduct a similar exercise as in the preceding section using a version of the Smets and Wouters (2007) model.

\subsection{Smets-Wouters Type Model}

The model employed in this section is a slightly simplified version of the Smets and Wouters (2007) model. This version differs from their original model in the following three aspects. First, for the purpose of comparison with our baseline experiment, the monetary policy rule is replaced with the one specified in our baseline model whereas Smets and Wouters employ a generalized Taylor rule in which the policy rate is adjusted in response to the level and changes in the theoretical output gap (i.e., the gap between real output and output that would be obtained in the absence of nominal rigidities) in addition to inflation. Second, our structural shocks are all governed by stationary first-order autoregressive processes and their disturbances are mutually uncorrelated with each other. In the Smets-Wouters model, the exogenous spending disturbance is affected by a contemporaneous innovation to total factor productivity (TFP) and the price and wage markup disturbances follow $\operatorname{ARMA}(1,1)$ processes. Third, as in the baseline experiment, the binding shocks $m_{t}$ are incorporated into the monetary policy rule in 
order to take account of the zero lower bound constraint on the nominal interest rate in the DGP.

The model consists of the following log-linearized equations. ${ }^{10}$ In what follows, all the variables are expressed in terms of their percentage deviation from the steady-state balanced growth path.

$$
\begin{aligned}
& \tilde{c}_{t}=\frac{\lambda / \gamma}{1+\lambda / \gamma} \tilde{c}_{t-1}+\frac{1}{1+\lambda / \gamma} E_{t} \tilde{c}_{t+1}+\frac{\left(\sigma_{c}-1\right) w^{h} l / c}{\sigma_{c}(1+\lambda / \gamma)}\left(\tilde{l}_{t}-E_{t} \tilde{l}_{t+1}\right) \\
& -\frac{1-\lambda / \gamma}{\sigma_{c}(1+\lambda / \gamma)}\left(\tilde{r}_{t}-E_{t} \tilde{\pi}_{t+1}+\varepsilon_{t}^{b}\right) \\
& \tilde{\imath}_{t}=\frac{1}{1+\beta \gamma^{1-\sigma_{c}}} \tilde{t}_{t-1}+\frac{\beta \gamma^{1-\sigma_{c}}}{1+\beta \gamma^{1-\sigma_{c}}} E_{t} \tilde{\imath}_{t+1}+\frac{1}{\gamma^{2} \varphi\left(1+\beta \gamma^{1-\sigma_{c}}\right)} \tilde{q}_{t}+\varepsilon_{t}^{i} \text {, } \\
& \tilde{q}_{t}=\frac{1-\delta}{r^{k}+1-\delta} E_{t} \tilde{q}_{t+1}+\frac{r^{k}}{r^{k}+1-\delta} E_{t} \tilde{r}_{t+1}^{k}-\left(\tilde{r}_{t}-E_{t} \tilde{\pi}_{t+1}+\varepsilon_{t}^{b}\right) \text {, } \\
& \tilde{y}_{t}=\phi_{p}\left[\alpha \tilde{k}_{t}^{s}+(1-\alpha) \tilde{l}_{t}+\varepsilon_{t}^{a}\right] \text {, } \\
& \tilde{k}_{t}^{s}=\tilde{z}_{t}+\tilde{k}_{t-1} \text {, } \\
& \tilde{z}_{t}=\frac{1-\psi}{\psi} \tilde{r}_{t}^{k} \\
& \tilde{k}_{t}=\frac{1-\delta}{\gamma} \tilde{k}_{t-1}+\left(1-\frac{1-\delta}{\gamma}\right)\left[\tilde{\imath}_{t}+\gamma^{2} \varphi\left(1+\beta \gamma^{1-\sigma_{c}}\right) \varepsilon_{t}^{i}\right] \text {, } \\
& \tilde{y}_{t}=c_{y} \tilde{c}_{t}+i_{y} \tilde{\imath}_{t}+r^{k} k_{y} \tilde{z}_{t}+\varepsilon_{t}^{g} \text {, } \\
& \tilde{\mu}_{t}^{p}=\alpha\left(\tilde{k}_{t}^{s}-\tilde{l}_{t}\right)-\tilde{w}_{t} \\
& \tilde{\pi}_{t}=\frac{\iota_{p}}{1+\beta \gamma^{1-\sigma_{c} \iota_{p}}} \tilde{\pi}_{t-1}+\frac{\beta \gamma^{1-\sigma_{c}}}{1+\beta \gamma^{1-\sigma_{c} \iota_{p}}} E_{t} \tilde{\pi}_{t+1} \\
& -\frac{\left(1-\xi_{p}\right)\left(1-\beta \gamma^{1-\sigma_{c}} \xi_{p}\right)}{\xi_{p}\left(1+\beta \gamma^{1-\sigma_{c}} \iota_{p}\right)\left[\left(\phi_{p}-1\right) \varepsilon_{p}+1\right]} \tilde{\mu}_{t}^{p}+\varepsilon_{t}^{p} \\
& \tilde{r}_{t}^{k}=-\left(\tilde{k}_{t}^{s}-\tilde{l}_{t}\right)+\tilde{w}_{t} \\
& \tilde{\mu}_{t}^{w}=\tilde{w}_{t}-\left\{\sigma_{l} \tilde{l}_{t}+\frac{1}{1-\lambda / \gamma}\left[\tilde{c}_{t}-\frac{\lambda}{\gamma} \tilde{c}_{t-1}\right]\right\} \\
& \tilde{w}_{t}=\frac{1}{1+\beta \gamma^{1-\sigma_{c}}} \tilde{w}_{t-1}+\frac{\beta \gamma^{1-\sigma_{c}}}{1+\beta \gamma^{1-\sigma_{c}}}\left(E_{t} \tilde{w}_{t+1}+E_{t} \tilde{\pi}_{t+1}\right)-\frac{1+\beta \gamma^{1-\sigma_{c}} \iota_{w}}{1+\beta \gamma^{1-\sigma_{c}}} \tilde{\pi}_{t} \\
& +\frac{\iota_{w}}{1+\beta \gamma^{1-\sigma_{c}}} \tilde{\pi}_{t-1}-\frac{\left(1-\xi_{w}\right)\left(1-\beta \gamma^{1-\sigma_{c}} \xi_{w}\right)}{\xi_{w}\left(1+\beta \gamma^{1-\sigma_{c}}\right)\left[\left(\phi_{w}-1\right) \varepsilon_{w}+1\right]} \tilde{\mu}_{t}^{w}+\varepsilon_{t}^{w}, \\
& \tilde{r}_{t}=r_{r} \tilde{r}_{t-1}+\left(1-r_{r}\right)\left(r_{\pi} \tilde{\pi}_{t}+r_{y} \tilde{y}_{t}\right)+\varepsilon_{t}^{r}+m_{t}
\end{aligned}
$$

Eq. (6) is the consumption Euler equation, where $\tilde{c}_{t}$ denotes consumption, $\tilde{l}_{t}$ is labor input,

\footnotetext{
${ }^{10}$ See the appendix to Smets and Wouters (2007) for a full description of the model.
} 
$\tilde{r}_{t}$ is the short-term nominal interest rate, $\tilde{\pi}_{t}$ is the inflation rate, $\varepsilon_{t}^{b}$ captures the risk premium shock in the return on assets held by households, $\lambda$ is the degree of external habit persistence in consumption preferences, $\gamma$ is the steady-state growth rate, $\sigma_{c}$ is the degree of relative risk aversion, and $w^{h} l / c$ is the steady-state value of labor relative to consumption. Eq. (7) is the investment adjustment equation, where $\tilde{\imath}_{t}$ represents investment, $\tilde{q}_{t}$ denotes the real value of the existing capital stock, $\varepsilon_{t}^{i}$ represents the shock to investment efficiency, $\beta$ is the subjective discount factor, and $\varphi$ is the steady-state elasticity of investment adjustment costs. Eq. (8) is the no-arbitrage condition for the value of capital, where $\tilde{r}_{t}^{k}$ is the real rental rate of capital, $\delta$ is the depreciation rate of capital, and $r^{k}$ is the steady-state real rental rate of capital. Eq. (9) is the Cobb-Douglas production function with fixed costs where $\tilde{y}_{t}$ denotes output, $\tilde{k}_{t}^{s}$ is effective capital services, $\varepsilon_{t}^{a}$ represents the TFP shock, $\phi_{p}$ is one plus the share of fixed costs in output, $\alpha$ is the share of capital in production. Eq. (10) gives the effective capital services used in production, where $\tilde{z}_{t}$ and $\tilde{k}_{t-1}$ denote the capital utilization rate and capital installed in the previous period. Eq. (11) is the condition for the capital utilization rate, where $\psi$ is determined by a function of the steady-state elasticity of the rate adjustment costs. Eq. (12) is the capital accumulation equation. Eq. (13) is the aggregate resource constraint, where $\varepsilon_{t}^{g}$ represents the exogenous spending shock, $c_{y}, i_{y}, k_{y}$ are the steady-state output ratios of consumption, investment, and capital. Eq. (14) is the equation for the price markup $\tilde{\mu}_{t}^{p}$, where $\tilde{w}_{t}$ is the real wage. Eq. (15) is the New Keynesian Phillips curve, where $\varepsilon_{t}^{p}$ represents the price markup shock, $\xi_{p}$ and $\iota_{p}$ are the degrees of price stickiness and price indexation to past inflation, $\left(\phi_{p}-1\right)$ is the steady-state goods market markup, and $\varepsilon_{p}$ is the curvature of the Kimball (1995) goods market aggregator. Eq. (16) is the condition for capital and labor inputs in production. Eq. (17) is the equation for the wage markup $\tilde{\mu}_{t}^{w}$, where $\sigma_{l}$ is the inverse elasticity of labor supply. Eq. (18) is the wage equation, where $\varepsilon_{t}^{w}$ represents the wage markup shock, $\xi_{w}$ and $\iota_{w}$ are the degrees of wage stickiness and wage indexation to past inflation, $\left(\phi_{w}-1\right)$ is the steady-state labor market markup, and $\varepsilon_{w}$ is the curvature of the Kimball (1995) labor market aggregator. Eq. (19) is the monetary policy rule, where $r_{r}$ is the degree of interest rate smoothing, $r_{\pi}$ and $r_{y}$ represent the degrees of interest rate policy responses to inflation and output gap, respectively, $\varepsilon_{t}^{r}$ is the monetary policy shock, and $m_{t}$ is the binding shock.

There are seven structural shocks in the model. Each of them $\varepsilon_{t}^{x}, x \in\{a, b, g, i, r, p, w\}$ 
follows

$$
\varepsilon_{t}^{x}=\rho_{x} \varepsilon_{t-1}^{x}+\eta_{t}^{x}, \quad \eta_{t}^{x} \sim \text { i.i.d. } \quad N\left(0, \sigma_{x}^{2}\right)
$$

where $\rho_{x}$ is an autoregressive coefficient and $\eta_{t}^{x}$ is a normally distributed innovation with mean zero and standard deviation $\sigma_{x}$.

The observation equations are

$$
\left[\begin{array}{c}
100 \Delta \log Y_{t} \\
100 \Delta \log C_{t} \\
100 \Delta \log I_{t} \\
100 \Delta \log W_{t} \\
100 \log l_{t} \\
100 \Delta \log P_{t} \\
100 \log r_{t}
\end{array}\right]=\left[\begin{array}{c}
\bar{\gamma} \\
\bar{\gamma} \\
\bar{\gamma} \\
\bar{\gamma} \\
\bar{l} \\
\bar{\pi} \\
\bar{r}
\end{array}\right]+\left[\begin{array}{c}
\tilde{y}_{t}-\tilde{y}_{t-1}+\varepsilon_{t}^{a} \\
\tilde{c}_{t}-\tilde{c}_{t-1}+\varepsilon_{t}^{a} \\
\tilde{\imath}_{t}-\tilde{\imath}_{t-1}+\varepsilon_{t}^{a} \\
\tilde{w}_{t}-\tilde{w}_{t-1}+\varepsilon_{t}^{a} \\
\tilde{l}_{t} \\
\tilde{\pi}_{t} \\
\tilde{r}_{t}
\end{array}\right],
$$

where $\bar{\gamma}=100(\gamma-1), \bar{l}$ is the steady-state hours worked, $\bar{\pi}=100(\pi-1)$, and $\bar{r}=100\left(\beta^{-1} \gamma^{\sigma_{c}} \pi-\right.$ $1)$.

\subsection{Parameter Setting and Prior Distribution}

The true parameter values that characterize the DGP basically follow from the prior means used in Smets and Wouters (2007), but some are changed so that the resulting probability of hitting the interest-rate lower bound is comparable (12 periods of 200) to that in our baseline experiment. To be specific, the steady-state inflation rate $\bar{\pi}$ is changed from 0.625 to 0.5 , and the standard deviations of the structural shocks $\sigma_{x}, x \in\{a, b, g, i, r, p, w\}$ are all changed from 0.1 to 0.3 .

Then, the model without the zero lower bound constraint is estimated using the artificial time series generated from the DGP presented above. The second to fourth columns in Table 5 summarize the prior distributions of parameters used for the estimation in the present experiment. As in the preceding experiments, each prior mean is set to the corresponding true parameter value. For the standard deviations of the prior distributions, we use the same values as set in Smets and Wouters (2007). 


\subsection{Results for the Robustness Experiment}

The last two columns in Table 5 show the posterior means and 90 percent credible intervals for the estimated parameters in the Smets-Wouters type model. As in the baseline experiment, most of the posterior mean estimates are almost the same as the true parameter values. However, substantial biases are detected in the estimates of the elasticity of investment adjustment $\operatorname{costs} \varphi$ and the monetary policy response to inflation $r_{\pi}$, that is, the 90 percent credible intervals for these two estimates do not contain their corresponding true values. The intuition about the bias in $\varphi$ is as follows. Without considering the interest-rate lower bound in the estimation, the model-implied interest rate series is biased. As the transmission effect of the change in the interest rate on investment is quite strong, the parameter $\varphi$ that characterizes the relationship between investment and the interest rate has to be biased in order to fit to the investment series generated from the DGP. Regarding the bias in $r_{\pi}$, the same explanation as provided in the previous section applies.

Figure 4 compares the estimated and true impulse responses of output, inflation, and the nominal interest rate to one standard deviation shocks regarding the TFP, the risk premium, external demand, investment, monetary policy, the price markup, and the wage markup. As with the preceding experiments, in each panel, the solid thick line represents the true response, the solid thin and dashed lines are respectively the posterior mean and 90 percent credible interval for the estimated response, and the responses are shown in terms of the percentage deviation from the steady state. A remarkable finding here is that as shown in almost all of the panels, the true responses lie in the estimated credible intervals, although some of the mean estimates differ from the true responses. Therefore, we reach the same conclusion as in the baseline experiment that the parameter biases from ignoring the zero lower bound constraint only have quite marginal effects on the properties of the model.

\section{Conclusion}

This paper has investigated the parameter biases in an estimated DSGE model that excludes the existence of the zero lower bound constraint on the nominal interest rate. To this end, we have conducted econometric experiments using a standard sticky-price DSGE model. According to the results in our baseline experiment, some biases are detected in the estimates of the 
monetary policy parameters and the steady-state real interest rate, but the estimates of the other structural parameters are not biased. However, we have demonstrated that the parameter biases become large with the increased probability of hitting the zero lower bound. The last finding cautions researchers against the common practice of estimating linearized DSGE models without considering the lower bound.

However, as Braun, Körber, and Waki (2012) and Gust, López-Salido, and Smith (2012) suggest, the solution algorithm in which nonlinearity is considered only in monetary policy rules but the remaining equilibrium conditions are linearized may lead to an inaccurate assessment of the lower bound constraint. In this regard, it is an important research agenda to examine how parameter estimates in linearized DSGE models can be affected by ignoring the true economic structures characterized by fully nonlinear models. 


\section{Appendix}

This appendix presents the full description of the model. In the model economy, there are a continuum of households, a representative final-good firm, a continuum of intermediate-good firms, and a monetary authority.

Each household $h \in[0,1]$ consumes final goods $C_{h, t}$, supplies labor $l_{h, t}$, and purchases one-period riskless bonds $B_{h, t}$ so as to maximize the utility function

$$
E_{0} \sum_{t=0}^{\infty} \beta^{t}\left[\frac{\left(C_{h, t}-\gamma C_{t-1}\right)^{1-\sigma}}{1-\sigma}-\frac{l_{h, t}^{1+\chi}}{1+\chi}\right]
$$

subject to the budget constraint

$$
P_{t} C_{h, t}+B_{h, t}=P_{t} W_{t} l_{h, t}+r_{t-1}^{n} B_{h, t-1}+T_{h, t},
$$

where $E_{t}$ is the expectation operator conditional on information available in period $t, \beta \in$ $(0,1)$ is the subjective discount factor, $\sigma>0$ is the inverse of the intertemporal elasticity of substitution, $\gamma \in[0,1]$ is the degree of external habit persistence in consumption preferences, $\chi>0$ is the inverse of the elasticity of labor supply, $P_{t}$ is the price of final goods, $W_{t}$ is the real wage, $r_{t}^{n}$ is the gross nominal interest rate, and $T_{h, t}$ is the sum of a lump-sum public transfer and profits received from firms. The first-order conditions for optimal decisions on consumption, labor supply, and bond-holding are identical among households and therefore become

$$
\begin{aligned}
\Lambda_{t} & =\left(C_{t}-\gamma C_{t-1}\right)^{-\sigma}, \\
W_{t} & =\frac{l_{t}^{\chi}}{\Lambda_{t}}, \\
1 & =E_{t} \beta \frac{\Lambda_{t+1}}{\Lambda_{t}} \frac{r_{t}^{n}}{\pi_{t+1}},
\end{aligned}
$$

where $\Lambda_{t}$ is the marginal utility of consumption and $\pi_{t}=P_{t} / P_{t-1}$ denotes gross inflation.

The representative final-good firm produces output $Y_{t}$ under perfect competition by choosing a combination of intermediate inputs $\left\{Y_{f, t}\right\}$ so as to maximize profit $P_{t} Y_{t}-\int_{0}^{1} P_{f, t} Y_{f, t} d f$ subject to a CES production technology $Y_{t}=\left(\int_{0}^{1} Y_{f, t}^{1 /\left(1+\lambda^{p}\right)} d f\right)^{1+\lambda^{p}}$, where $P_{f, t}$ is the price of intermediate good $f$ and $\lambda^{p} \geq 0$ denotes the intermediate-good price markup. The first-order condition for profit maximization yields the final-good firm's demand for intermediate good f, $Y_{f, t}=Y_{t}\left(P_{f, t} / P_{t}\right)^{-\left(1+\lambda^{p}\right) / \lambda^{p}}$, while perfect competition in the final-good market leads to $P_{t}=\left(\int_{0}^{1} P_{f, t}^{-1 / \lambda^{p}} d f\right)^{-\lambda^{p}}$. 
Each intermediate-good firm $f$ produces one kind of differentiated goods $Y_{f, t}$ under monopolistic competition by choosing a cost-minimizing labor input $l_{t}$ given the real wage $W_{t}$ subject to the production function

$$
Y_{f, t}=A_{t} l_{f, t}
$$

where $A_{t}$ represents the exogenous technology level. The first-order condition for cost minimization shows that real marginal cost is identical among intermediate-good firms and is given by

$$
m c_{t}=\frac{W_{t}}{A_{t}} .
$$

In the face of the final-good firm's demand and marginal cost, the intermediate-good firms set prices of their products on a staggered basis as in Calvo (1983). In each period, a fraction $1-\xi \in(0,1)$ of intermediate-good firms re-optimize their prices while the remaining fraction $\xi$ indexes prices to a weighted average of past inflation $\pi_{t-1}$ and steady-state inflation $\pi$. The firms that re-optimize their prices in the current period then maximize expected profit

$$
E_{t} \sum_{j=0}^{\infty} \xi^{j} \frac{\beta^{j} \Lambda_{t+j}}{\Lambda_{t}}\left[\frac{P_{f, t}}{P_{t+j}} \prod_{k=1}^{j}\left(\pi_{t+k-1}^{\iota} \pi^{1-\iota}\right)-m c_{t+j}\right] Y_{f, t+j}
$$

subject to the final-good firm's demand

$$
Y_{f, t+j}=Y_{t+j}\left[\frac{P_{f, t}}{P_{t+j}} \prod_{k=1}^{j}\left(\pi_{t+k-1}^{\iota} \pi^{1-\iota}\right)\right]^{-\frac{1+\lambda^{p}}{\lambda^{p}}},
$$

where $\iota \in(0,1)$ denotes the weight of price indexation to past inflation relative to steady-state inflation. The first-order condition for the reoptimized price $P_{t}^{o}$ is given by

$$
E_{t} \sum_{j=0}^{\infty}\left\{\begin{array}{c}
(\beta \xi)^{j} \frac{\Lambda_{t+j}}{\Lambda_{t}} Y_{t+j}\left[\frac{P_{t}^{o}}{P_{t}} \prod_{k=1}^{j}\left(\frac{\pi_{t+k-1}}{\pi}\right)^{\iota} \frac{\pi}{\pi_{t+k}}\right]^{-\frac{1+\lambda^{p}}{\lambda p}} \\
\times\left[\frac{P_{t}^{o}}{P_{t}} \prod_{k=1}^{j}\left(\frac{\pi_{t+k-1}}{\pi}\right)^{\iota} \frac{\pi}{\pi_{t+k}}-\left(1+\lambda^{p}\right) m c_{t+j}\right]
\end{array}\right\}=0 .
$$

Moreover, the final-good's price $P_{t}=\left(\int_{0}^{1} P_{f, t}^{-1 / \lambda^{p}} d f\right)^{-\lambda^{p}}$ can be rewritten as

$$
1=(1-\xi)\left(\frac{P_{t}^{o}}{P_{t}}\right)^{-\frac{1}{\lambda^{p}}}+\xi\left[\left(\frac{\pi_{t-1}}{\pi}\right)^{\iota} \frac{\pi}{\pi_{t}}\right]^{-\frac{1}{\lambda^{p}}} .
$$

The final-good market clearing condition is

$$
Y_{t}=C_{t},
$$


while the labor market clearing condition leads to

$$
\frac{Y_{t} d_{t}}{A_{t}}=\int_{0}^{1} l_{f, t} d f=l_{t}
$$

where $d_{t}=\int_{0}^{1}\left(P_{f, t} / P_{t}\right)^{-\left(1+\lambda^{p}\right) / \lambda^{p}} d f$ represents price dispersion across the intermediate-good firms. Note that this dispersion is of second-order under the staggered price setting and that its steady-state value is unity.

A monetary policy rule is specified as

$$
\log r_{t}^{n}=\max \left[\phi_{r} \log r_{t-1}^{n}+\left(1-\phi_{r}\right)\left(\log r^{n}+\phi_{\pi} \log \frac{\pi_{t}}{\pi}+\phi_{y} \log \frac{Y_{t}}{Y}\right)+z_{t}^{r}, 0\right] .
$$

In the absence of the zero lower bound on the nominal interest rate, the monetary authority adjusts the interest rate following a Taylor (1993) type monetary policy rule where $\phi_{r} \in[0,1)$ is the degree of interest rate smoothing, $r^{n}$ is the steady-state gross nominal interest rate, and $\phi_{\pi}, \phi_{y} \geq 0$ are the degrees of interest rate policy responses to inflation and output. $z_{t}^{r}$ is a monetary policy shock, which captures unsystematic components of monetary policy.

The equilibrium conditions are (A.1)-(A.9). Log-linearizing the equilibrium conditions around the steady state and rearranging the resulting equations yields Eq. (1)-(3). The demand shock $z_{t}^{d}$ and cost shock $z_{t}^{p}$ have been introduced in a reduced form manner, and interpreted as a shock to consumption preferences and time-varying price markup of intermediate-goods respectively. 


\section{References}

[1] Adam, Klaus, and Roberto M. Billi, 2006. "Optimal Monetary Policy under Commitment with a Zero Bound on Nominal Interest Rates." Journal of Money, Credit and Banking, 38(7), 1877-1905.

[2] Adam, Klaus, and Roberto M. Billi, 2007. "Discretionary monetary policy and the zero lower bound on nominal interest rates." Journal of Monetary Economics, 54(3), 728-752.

[3] Aruoba, S. Borağan, and Frank Schorfheide, 2013. "Macroeconomic Dynamics Near the ZLB: A Tale of Two Equilibria." NBER Working Paper 19248, National Bureau of Economic Research.

[4] Blanchard, Olivier J., and Charles M. Kahn, 1980. "The Solution of Linear Difference Models under Rational Expectations." Econometrica, 48, 1305-1311.

[5] Bodenstein, Martin, Luca Guerrieri, and Christopher J. Gust, 2013. "Oil Shocks and the Zero Bound on Nominal Interest Rates." Journal of International Money and Finance, 32, 941-967.

[6] Braun, R. Anton, Lena M. Körber, and Yuichiro Waki, 2012. "Some Unpleasant Properties of Log-Linearized Solutions When the Nominal Rate is Zero." Working Paper 2012-05a, Federal Reserve Bank of Atlanta.

[7] Brooks, Stephen P., and Andrew Gelman, 1998. "General Methods for Monitoring Convergence of Iterative Simulations." Journal of Computational and Graphical Statistics, 7(4), $434-455$.

[8] Calvo, Guillermo A., 1983. "Staggered Prices in a Utility-Maximizing Framework." Journal of Monetary Economics, 12(3), 383-398.

[9] Christiano, Lawrence, Martin Eichenbaum, and Sergio Rebelo, 2011. "When Is the Government Spending Multiplier Large?" Journal of Political Economy, 119(1), 78-121.

[10] Dennis, Richard, 2004. "Specifying and estimating New Keynesian Models with Instrument Rules and Optimal Monetary Policies." Working Paper 2004-17, Federal Reserve Bank of San Francisco. 
[11] Dennis, Richard, 2009. "Consumption Habits in a New Keynesian Business Cycle Model." Journal of Money, Credit and Banking, 41(5), 1015-1030.

[12] Eggertsson, Gauti B., and Michael Woodford, 2003. "The Zero Bound on Interest Rates and Optimal Monetary Policy." Brookings Papers on Economic Activity 34(1), 139-235.

[13] Erceg, Christopher J., and Jesper Lindé, 2012. "Is There a Fiscal Free Lunch in a Liquidity Trap." Journal of European Economic Association, forthcoming.

[14] Fernández-Villaverde, Jesús, Grey Gordon, Pablo A. Guerrón-Quintana, and Juan RubioRamírez, 2012. "Nonlinear Adventures at the Zero Lower Bound." NBER Working Paper 18058, National Bureau of Economic Research.

[15] Gavin, William T., Benjamin D. Keen, Alexander Richter, and Nathaniel Throckmorton, 2013. "Global Dynamics at the Zero Lower Bound." Working Papers 2013-007, Federal Reserve Bank of St. Louis.

[16] Gust, Christopher, David Lopez-Salido, and Matthew E. Smith, 2012. "The Empirical Implications of the Interest-Rate Lower Bound." Finance and Economics Discussion Series 2012-83, Board of Governors of the Federal Reserve System.

[17] Jung, Taehun, Yuki Teranishi, and Tsutomu Watanabe, 2005. "Optimal Monetary Policy at the Zero-Interest-Rate Bound." Journal of Money Credit and Banking, 37(5) 813-835.

[18] Kimball, Miles S., 1995. "The Quantitative Analytics of the Basic Neomonetarist Model." Journal of Money Credit and Banking, 27(4) 1241-1277.

[19] Laséen, Stefan, and Lars E.O. Svensson, 2011. "Anticipated Alternative policy Rate Paths in Policy Simulations." International Journal of Central Banking, 7(3), 1-35.

[20] Lubik, Thomas A., and Frank Schorfheide, 2004. "Testing for Indeterminacy: An Application to U.S. Monetary Policy." American Economic Review, 94(1), 190-217.

[21] Milani, Fabio, and John Treadwell, 2012. "The Effects of Monetary Policy 'News' and 'Surprises'." Journal of Money, Credit and Banking, 44(8), 1667-1692.

[22] Sims, Christopher A., 2002. "Solving Linear Rational Expectations Models." Computational Economics, 20, 1-20. 
[23] Smets, Frank, and Rafael Wouters, 2003. "An Estimated Dynamic Stochastic General Equilibrium Model of the Euro Area." Journal of the European Economic Association, $1(5), 1123-1175$.

[24] Smets, Frank, and Rafael Wouters, 2007. "Shocks and Frictions in US Business Cycles: A Bayesian DSGE Approach." American Economic Review, 97(3), 586-606.

[25] Taylor, John B., 1993. "Discretion Versus Policy Rules in Practice." Carnegie-Rochester Conference Series on Public Policy, 39(1), 195-214. 
Table 1: Parameter setting

\begin{tabular}{llc}
\hline \hline Parameter & \multicolumn{1}{c}{ Economic interpretation } & Assigned value \\
\hline$\sigma$ & Inverse of intertemporal elasticity of substitution & 1.000 \\
$\chi$ & Inverse of elasticity of labor supply & 1.000 \\
$\gamma$ & Habit persistence & 0.500 \\
$\iota$ & Price indexation & 0.500 \\
$\xi$ & Price stickiness & 0.750 \\
$\phi_{\pi}$ & Policy response to inflation & 1.500 \\
$\phi_{y}$ & Policy response to output & 0.125 \\
$\phi_{r}$ & Interest rate smoothing & 0.500 \\
$\bar{\pi}$ & Steady-state inflation rate & 0.500 \\
$\bar{r}$ & Steady-state real interest rate & 0.500 \\
$\rho_{d}$ & Persistence of demand shock & 0.500 \\
$\rho_{p}$ & Persistence of cost shock & 0.500 \\
$\rho_{r}$ & Persistence of policy shock & 0.500 \\
$\sigma_{d}$ & Standard deviation of demand shock & 0.250 \\
$\sigma_{p}$ & Standard deviation of cost shock & 0.250 \\
$\sigma_{r}$ & Standard deviation of policy shock & 0.250 \\
\hline
\end{tabular}


Table 2: Prior distributions

\begin{tabular}{lccc}
\hline \hline Parameter & Distribution & Mean & Standard deviation \\
\hline$\sigma$ & Gamma & 1.000 & 0.150 \\
$\chi$ & Gamma & 1.000 & 0.150 \\
$\gamma$ & Beta & 0.500 & 0.150 \\
$\xi$ & Beta & 0.750 & 0.150 \\
$\iota$ & Beta & 0.500 & 0.150 \\
$\phi_{\pi}$ & Gamma & 1.500 & 0.150 \\
$\phi_{y}$ & Gamma & 0.125 & 0.150 \\
$\phi_{r}$ & Beta & 0.500 & 0.150 \\
$\bar{\pi}$ & Gamma & 0.500 & 0.150 \\
$\bar{r}$ & Gamma & 0.500 & 0.150 \\
$\rho_{d}$ & Beta & 0.500 & 0.150 \\
$\rho_{p}$ & Beta & 0.500 & 0.150 \\
$\rho_{r}$ & Beta & 0.500 & 0.150 \\
$\sigma_{d}$ & Inverse Gamma & 0.250 & 2.000 \\
$\sigma_{p}$ & Inverse Gamma & 0.250 & 2.000 \\
$\sigma_{r}$ & Inverse Gamma & 0.250 & 2.000 \\
\hline
\end{tabular}


Table 3: Posterior distributions of parameters in baseline experiment

\begin{tabular}{lcccccc}
\hline \hline & & \multicolumn{2}{c}{ Baseline } & & \multicolumn{2}{c}{ Large sample } \\
\cline { 7 - 8 } \cline { 6 - 7 } Parameter & True value & Mean & $90 \%$ interval & & Mean & $90 \%$ interval \\
\hline$\sigma$ & 1.000 & 1.054 & {$[0.829,1.278]$} & & 1.041 & {$[0.950,1.132]$} \\
$\chi$ & 1.000 & 1.002 & {$[0.752,1.240]$} & & 1.005 & {$[0.761,1.250]$} \\
$\gamma$ & 0.500 & 0.439 & {$[0.303,0.582]$} & & 0.467 & {$[0.434,0.501]$} \\
$\xi$ & 0.750 & 0.757 & {$[0.686,0.826]$} & & 0.785 & {$[0.765,0.806]$} \\
$\iota$ & 0.500 & 0.495 & {$[0.288,0.693]$} & & 0.479 & {$[0.413,0.541]$} \\
$\phi_{\pi}$ & 1.500 & 1.293 & {$[1.107,1.472]$} & & 1.216 & {$[1.158,1.272]$} \\
$\phi_{y}$ & 0.125 & 0.156 & {$[0.000,0.273]$} & & 0.125 & {$[0.094,0.156]$} \\
$\phi_{r}$ & 0.500 & 0.404 & {$[0.340,0.466]$} & & 0.455 & {$[0.440,0.469]$} \\
$\bar{\pi}$ & 0.500 & 0.474 & {$[0.344,0.595]$} & & 0.470 & {$[0.442,0.498]$} \\
$\bar{r}$ & 0.500 & 0.594 & {$[0.514,0.673]$} & & 0.539 & {$[0.522,0.556]$} \\
$\rho_{d}$ & 0.500 & 0.470 & {$[0.322,0.623]$} & & 0.516 & {$[0.482,0.550]$} \\
$\rho_{p}$ & 0.500 & 0.498 & {$[0.346,0.647]$} & & 0.466 & {$[0.415,0.515]$} \\
$\rho_{r}$ & 0.500 & 0.518 & {$[0.412,0.623]$} & & 0.498 & {$[0.474,0.522]$} \\
$\sigma_{d}$ & 0.250 & 0.265 & {$[0.217,0.310]$} & & 0.237 & {$[0.227,0.247]$} \\
$\sigma_{p}$ & 0.250 & 0.240 & {$[0.187,0.295]$} & & 0.228 & {$[0.216,0.240]$} \\
$\sigma_{r}$ & 0.250 & 0.281 & {$[0.240,0.319]$} & & 0.253 & {$[0.245,0.261]$} \\
\hline
\end{tabular}

Notes: In the baseline, the model is estimated using a sample of 200 observations. In the large sample case, the same model is estimated using a sample of 5,000 observations. 
Table 4: Posterior distributions of parameters in alternative experiments

\begin{tabular}{|c|c|c|c|c|c|}
\hline \multirow[b]{2}{*}{ Parameter } & \multirow[b]{2}{*}{ True value } & \multicolumn{2}{|c|}{ Case of low $\bar{r}$} & \multicolumn{2}{|c|}{ Case of large $\sigma_{d}$} \\
\hline & & Mean & $90 \%$ interval & Mean & $90 \%$ interval \\
\hline$\sigma$ & 1.000 & 1.086 & {$[0.855,1.326]$} & 0.953 & {$[0.731,1.175]$} \\
\hline$\chi$ & 1.000 & 0.997 & {$[0.761,1.248]$} & 0.994 & {$[0.746,1.232]$} \\
\hline$\gamma$ & 0.500 & 0.421 & {$[0.290,0.546]$} & 0.432 & {$[0.308,0.558]$} \\
\hline$\xi$ & 0.750 & 0.762 & {$[0.701,0.818]$} & 0.764 & {$[0.723,0.807]$} \\
\hline$\iota$ & 0.500 & 0.432 & {$[0.269,0.596]$} & 0.391 & {$[0.237,0.541]$} \\
\hline$\phi_{\pi}$ & 1.500 & 1.279 & {$[1.053,1.492]$} & 1.197 & {$[1.035,1.346]$} \\
\hline$\phi_{y}$ & 0.125 & 0.410 & {$[0.000,0.823]$} & 0.055 & {$[0.023,0.077]$} \\
\hline$\phi_{r}$ & 0.500 & 0.505 & {$[0.409,0.598]$} & 0.329 & {$[0.264,0.391]$} \\
\hline $\bar{\pi}$ & 0.500 & 0.413 & {$[0.266,0.560]$} & 0.471 & {$[0.307,0.628]$} \\
\hline $\bar{r}$ & 0.250 & 0.343 & {$[0.231,0.461]$} & - & - \\
\hline $\bar{r}$ & 0.500 & - & - & 0.722 & {$[0.617,0.831]$} \\
\hline$\rho_{d}$ & 0.500 & 0.527 & {$[0.415,0.643]$} & 0.516 & {$[0.403,0.634]$} \\
\hline$\rho_{p}$ & 0.500 & 0.486 & {$[0.349,0.622]$} & 0.615 & {$[0.498,0.733]$} \\
\hline$\rho_{r}$ & 0.500 & 0.642 & {$[0.583,0.702]$} & 0.642 & {$[0.557,0.727]$} \\
\hline$\sigma_{d}$ & 0.500 & - & - & 0.438 & {$[0.355,0.516]$} \\
\hline$\sigma_{d}$ & 0.250 & 0.266 & {$[0.220,0.310]$} & - & - \\
\hline$\sigma_{p}$ & 0.250 & 0.253 & {$[0.194,0.315]$} & 0.203 & {$[0.162,0.243]$} \\
\hline$\sigma_{r}$ & 0.250 & 0.426 & {$[0.337,0.515]$} & 0.302 & {$[0.264,0.338]$} \\
\hline
\end{tabular}

Notes: In the case of low $\bar{r}$, the true values are set at $\bar{r}=0.25$ and $\sigma_{d}=0.25$. In the case of large $\sigma_{d}$, the true values are set at $\bar{r}=0.5$ and $\sigma_{d}=0.5$. 
Table 5: Prior and posterior distributions of parameters in the Smets-Wouters type model

\begin{tabular}{|c|c|c|c|c|c|}
\hline \multirow[b]{2}{*}{ Parameter } & \multicolumn{3}{|c|}{ Prior distribution } & \multicolumn{2}{|c|}{ Posterior distribution } \\
\hline & Distribution & Mean & S.D. & Mean & $90 \%$ interval \\
\hline$\varphi$ & Normal & 4.000 & 1.500 & 4.852 & {$[4.071,5.641]$} \\
\hline$\sigma_{c}$ & Normal & 1.500 & 0.375 & 1.468 & {$[1.304,1.622]$} \\
\hline$\lambda$ & Beta & 0.700 & 0.100 & 0.728 & {$[0.685,0.769]$} \\
\hline$\xi_{w}$ & Beta & 0.500 & 0.100 & 0.503 & {$[0.442,0.559]$} \\
\hline$\sigma_{l}$ & Normal & 2.000 & 0.750 & 1.502 & {$[0.741,2.279]$} \\
\hline$\xi_{p}$ & Beta & 0.500 & 0.100 & 0.500 & {$[0.449,0.553]$} \\
\hline$\iota_{w}$ & Beta & 0.500 & 0.150 & 0.420 & {$[0.284,0.557]$} \\
\hline$\iota_{p}$ & Beta & 0.500 & 0.150 & 0.459 & {$[0.343,0.574]$} \\
\hline$\psi$ & Beta & 0.500 & 0.150 & 0.482 & {$[0.424,0.540]$} \\
\hline$\phi_{p}$ & Normal & 1.250 & 0.125 & 1.231 & {$[1.182,1.279]$} \\
\hline$r_{\pi}$ & Normal & 1.500 & 0.250 & 1.208 & {$[1.015,1.384]$} \\
\hline$\rho$ & Beta & 0.750 & 0.100 & 0.721 & {$[0.674,0.767]$} \\
\hline$r_{y}$ & Normal & 0.125 & 0.050 & 0.093 & {$[0.033,0.152]$} \\
\hline $\bar{\pi}$ & Gamma & 0.500 & 0.100 & 0.500 & {$[0.363,0.626]$} \\
\hline $100\left(\beta^{-1}-1\right)$ & Gamma & 0.250 & 0.100 & 0.191 & {$[0.087,0.291]$} \\
\hline $\bar{l}$ & Normal & 0.000 & 2.000 & -0.210 & {$[-0.673,0.241]$} \\
\hline $\bar{\gamma}$ & Normal & 0.400 & 0.100 & 0.399 & {$[0.397,0.402]$} \\
\hline$\alpha$ & Normal & 0.300 & 0.050 & 0.287 & {$[0.259,0.315]$} \\
\hline$\rho_{a}$ & Beta & 0.500 & 0.200 & 0.557 & {$[0.468,0.649]$} \\
\hline$\rho_{b}$ & Beta & 0.500 & 0.200 & 0.499 & {$[0.416,0.590]$} \\
\hline$\rho_{g}$ & Beta & 0.500 & 0.200 & 0.481 & {$[0.374,0.583]$} \\
\hline$\rho_{i}$ & Beta & 0.500 & 0.200 & 0.489 & {$[0.384,0.590]$} \\
\hline$\rho_{r}$ & Beta & 0.500 & 0.200 & 0.482 & {$[0.379,0.583]$} \\
\hline$\rho_{p}$ & Beta & 0.500 & 0.200 & 0.520 & {$[0.406,0.642]$} \\
\hline$\rho_{w}$ & Beta & 0.500 & 0.200 & 0.445 & {$[0.339,0.544]$} \\
\hline$\sigma_{a}$ & Inv. Gamma & 0.300 & 2.000 & 0.314 & {$[0.286,0.343]$} \\
\hline$\sigma_{b}$ & Inv. Gamma & 0.300 & 2.000 & 0.318 & {$[0.266,0.370]$} \\
\hline$\sigma_{g}$ & Inv. Gamma & 0.300 & 2.000 & 0.303 & {$[0.276,0.328]$} \\
\hline$\sigma_{i}$ & Inv. Gamma & 0.300 & 2.000 & 0.278 & {$[0.237,0.320]$} \\
\hline$\sigma_{r}$ & Inv. Gamma & 0.300 & 2.000 & 0.290 & {$[0.262,0.317]$} \\
\hline$\sigma_{p}$ & Inv. Gamma & 0.300 & 2.000 & 0.312 & {$[0.266,0.356]$} \\
\hline$\sigma_{w}$ & Inv. Gamma & 0.300 & 2.000 & 0.308 & {$[0.263,0.352]$} \\
\hline
\end{tabular}


Figure 1: Impulse responses in baseline experiment

(1) Demand shock
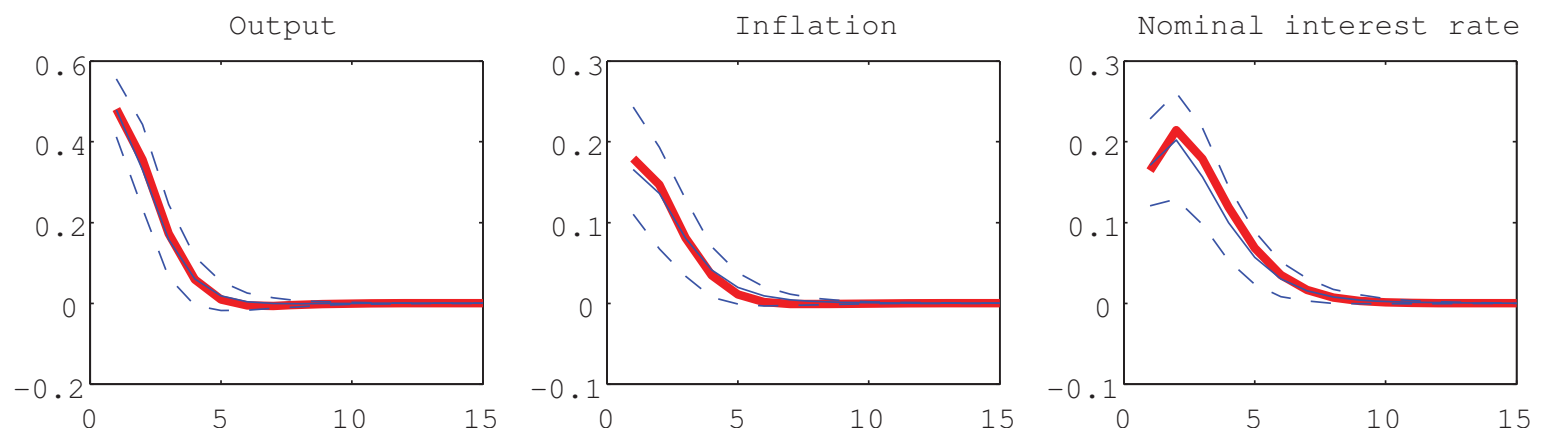

(2) Cost-push shock
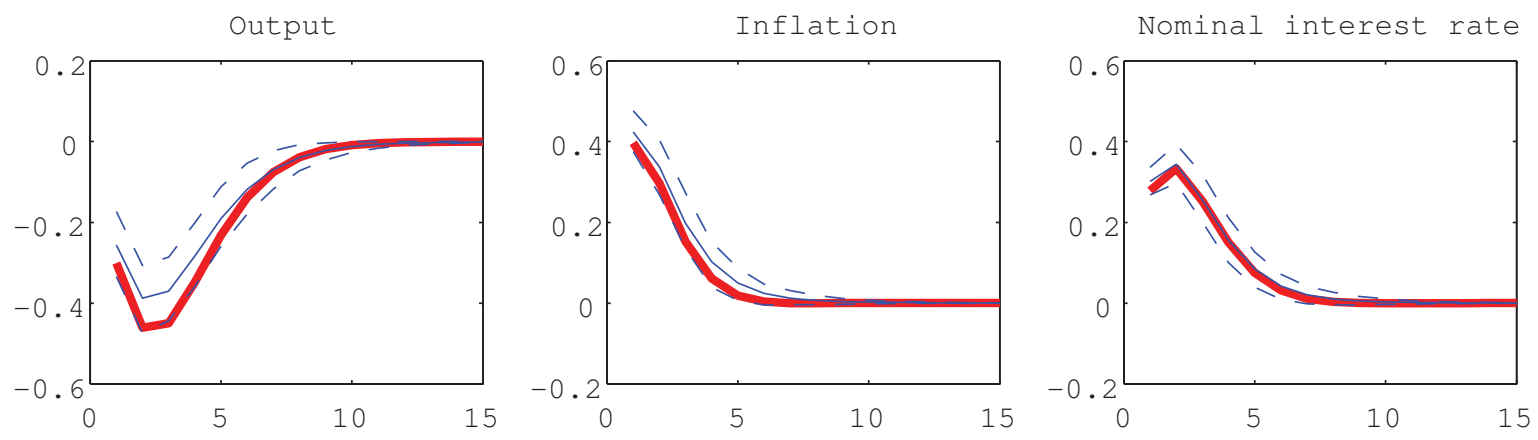

(3) Monetary policy shock
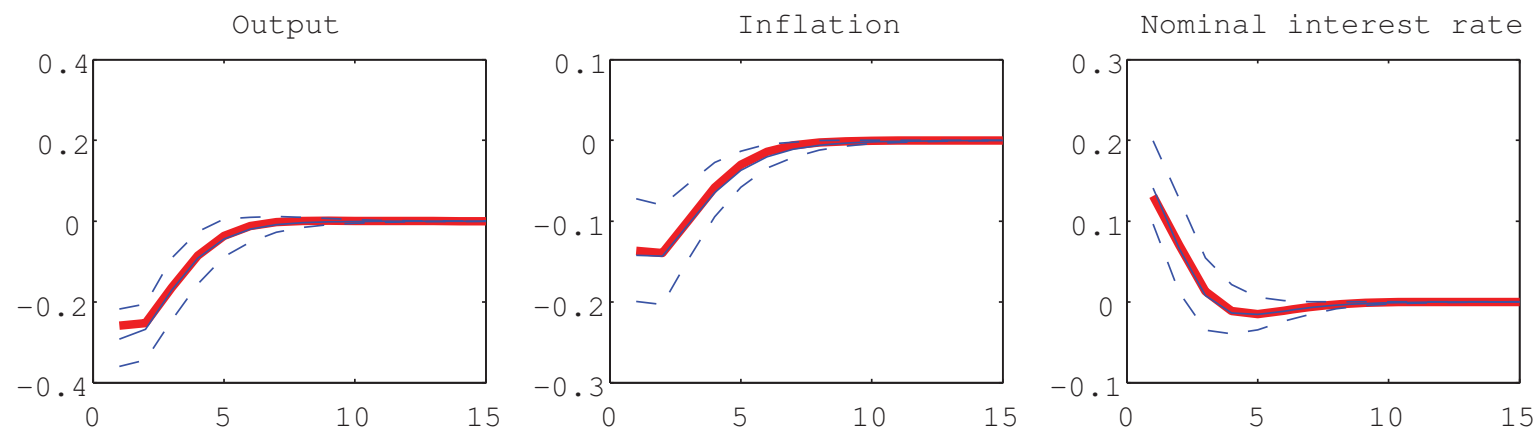

Notes: The figure shows the impulse responses of output, inflation, and the nominal interest rate (in terms of the percentage deviation from the steady state) to one standard deviation demand, cost-push, and monetary policy shocks. The solid thick lines represent the true responses, and the solid thin lines and dashed lines are respectively the posterior means and 90 percent credible intervals for the estimated responses. 
Figure 2: Impulse responses in alternative case I $(\bar{r}=0.25)$

(1) Demand shock
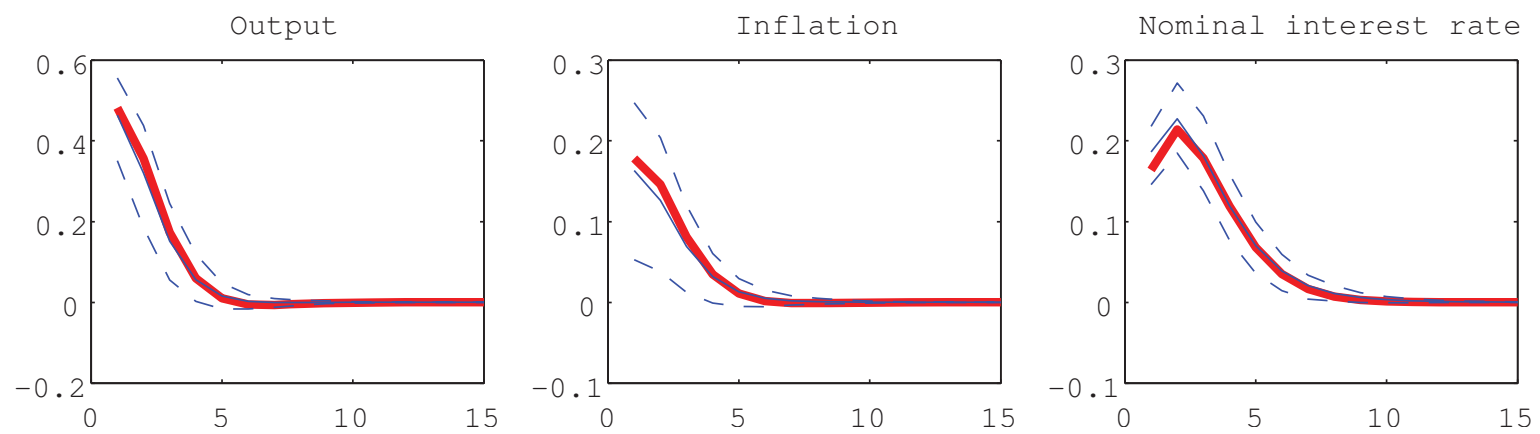

(2) Cost-push shock
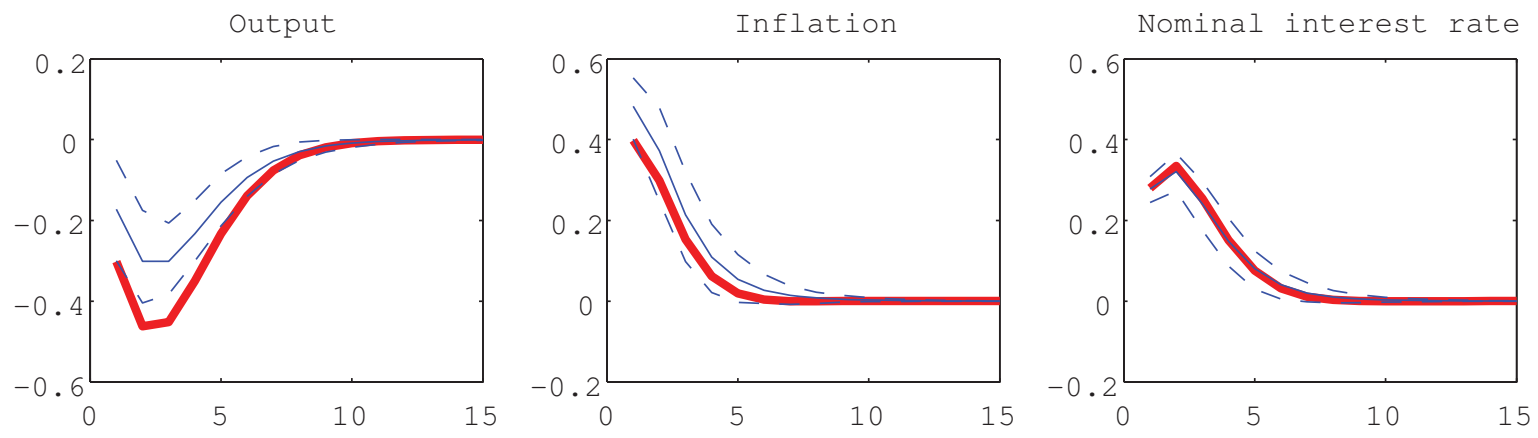

(3) Monetary policy shock
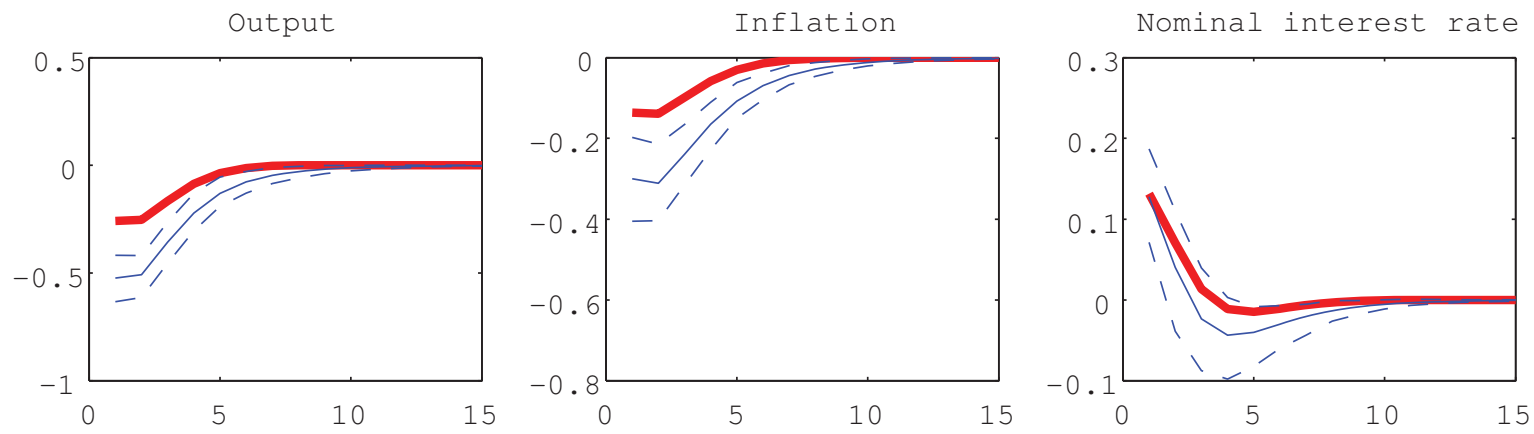

Notes: The figure shows the impulse responses of output, inflation, and the nominal interest rate (in terms of the percentage deviation from the steady state) to one standard deviation demand, cost-push, and monetary policy shocks. The solid thick lines represent the true responses, and the solid thin lines and dashed lines are respectively the posterior means and 90 percent credible intervals for the estimated responses. 
Figure 3: Impulse responses in alternative case II $\left(\sigma_{d}=0.5\right)$

(1) Demand shock
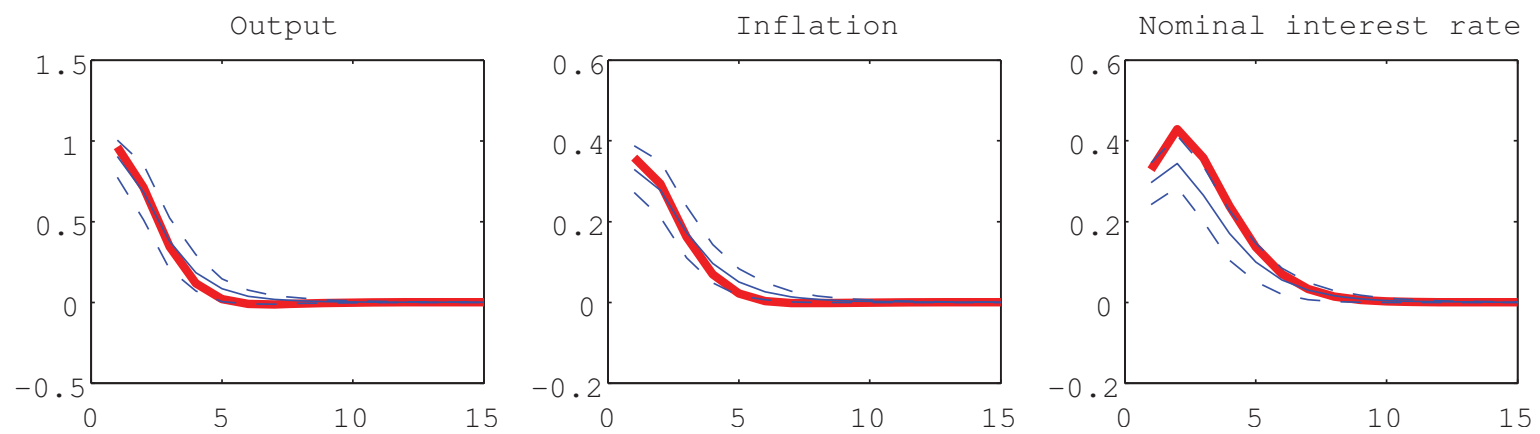

(2) Cost-push shock
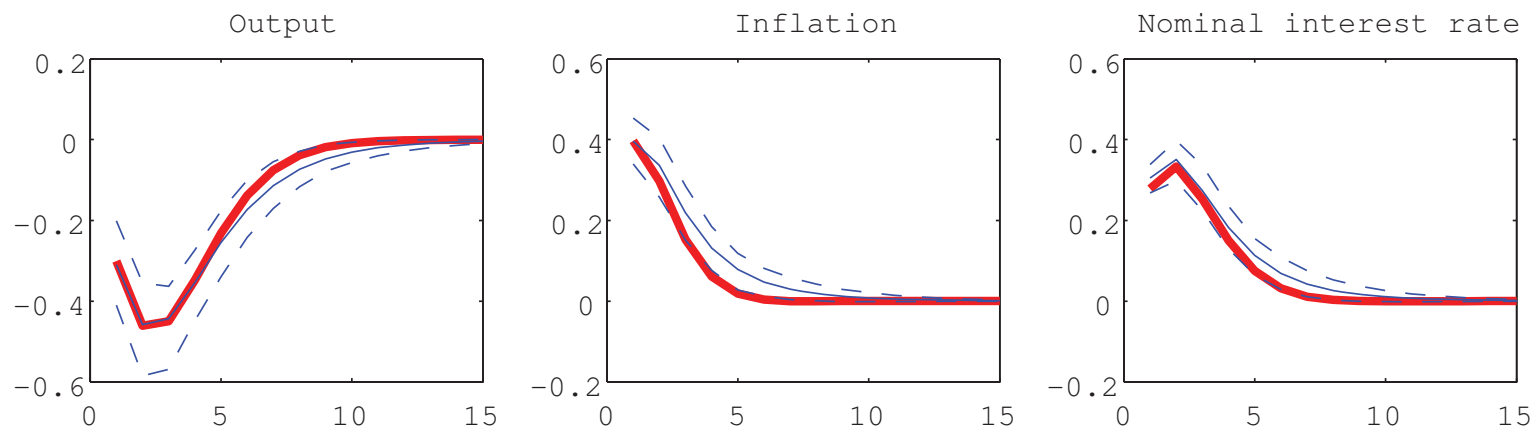

(3) Monetary policy shock
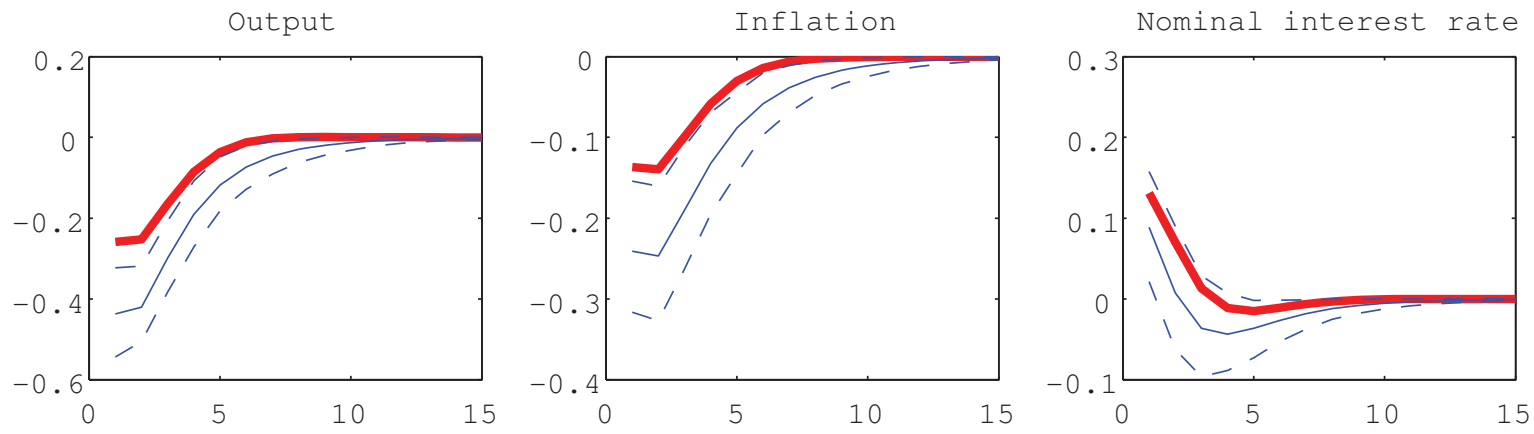

Notes: The figure shows the impulse responses of output, inflation, and the nominal interest rate (in terms of the percentage deviation from the steady state) to one standard deviation demand, cost-push, and monetary policy shocks. The solid thick lines represent the true responses, and the solid thin lines and dashed lines are respectively the posterior means and 90 percent credible intervals for the estimated responses. 
(1) TFP shock

Figure 4: Impulse responses in robustness analysis
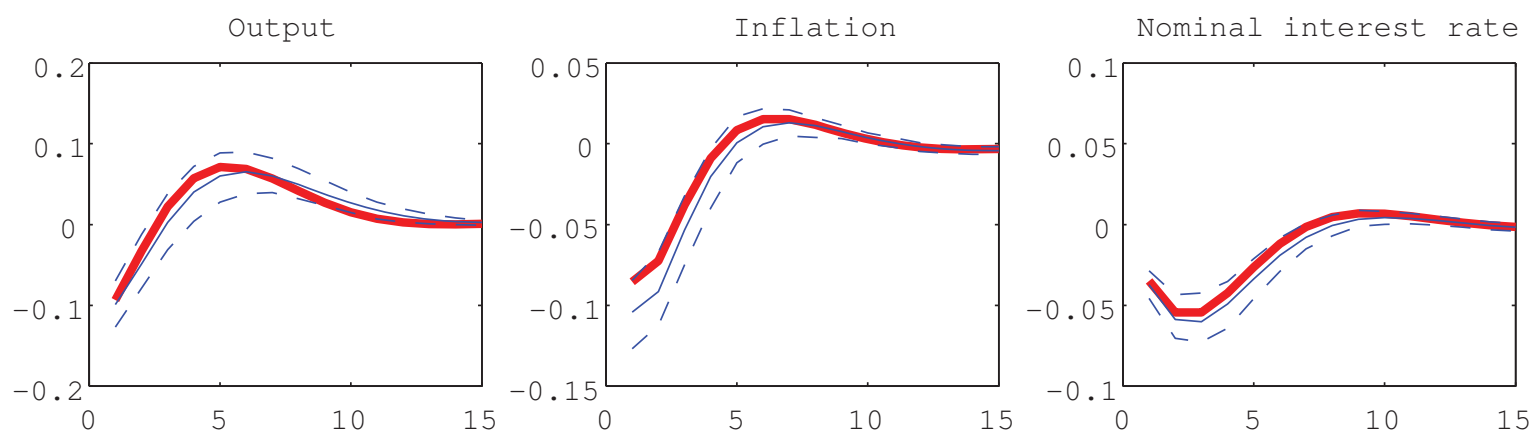

(2) Risk premium shock
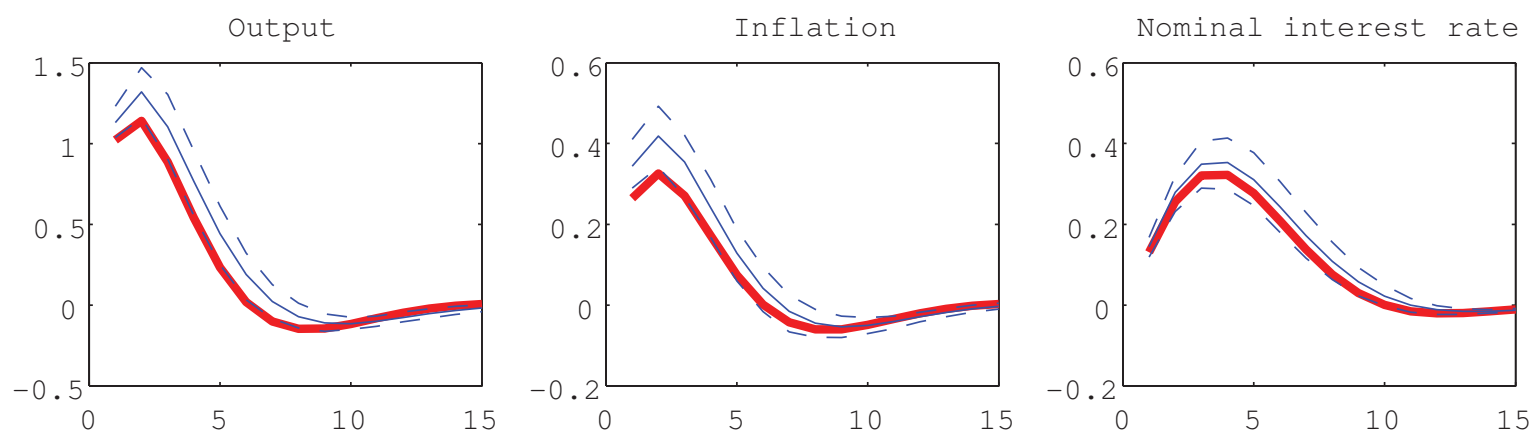

(3) External demand shock
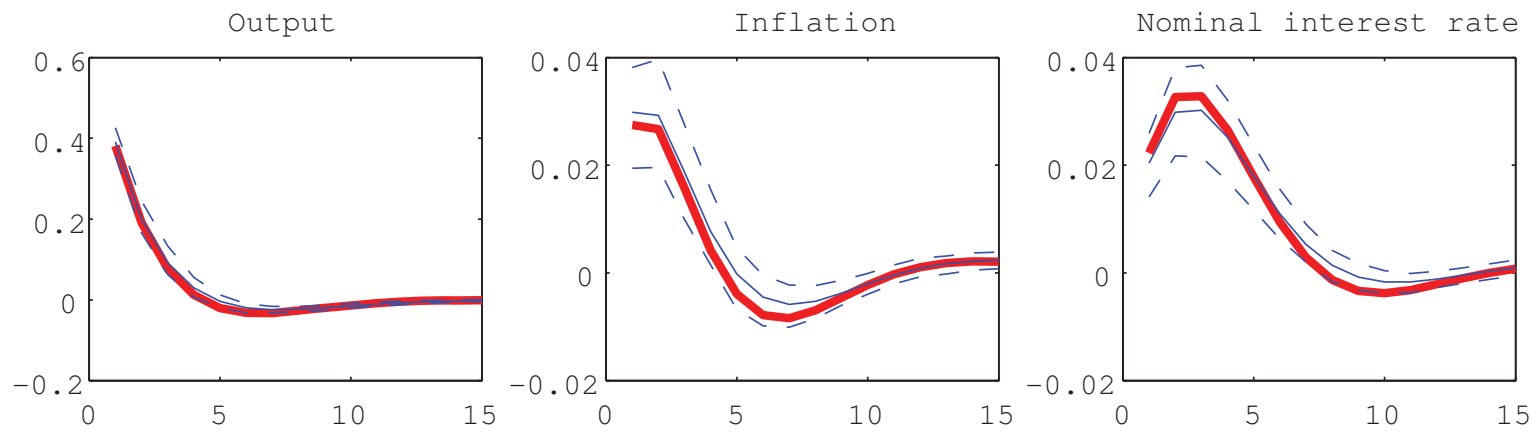

(4) Investment shock
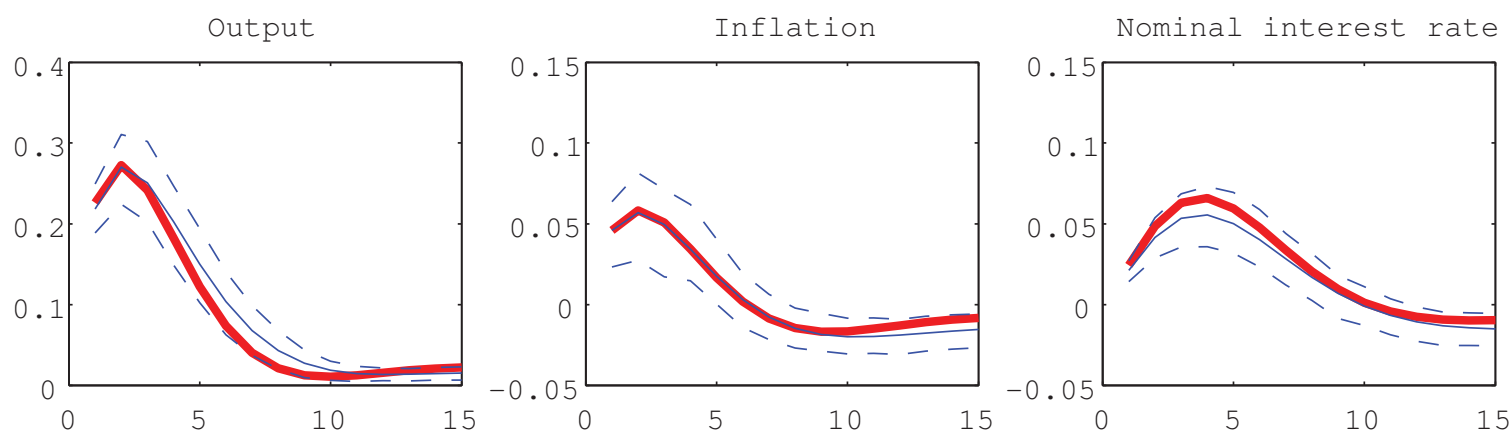
(5) Monetary policy shock
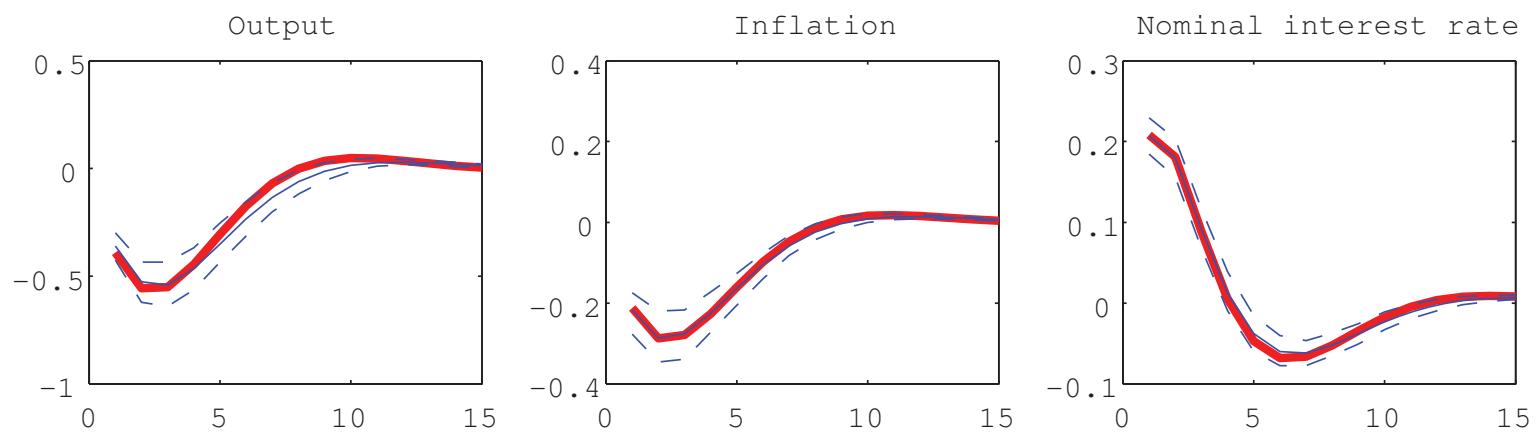

(6) Price markup shock
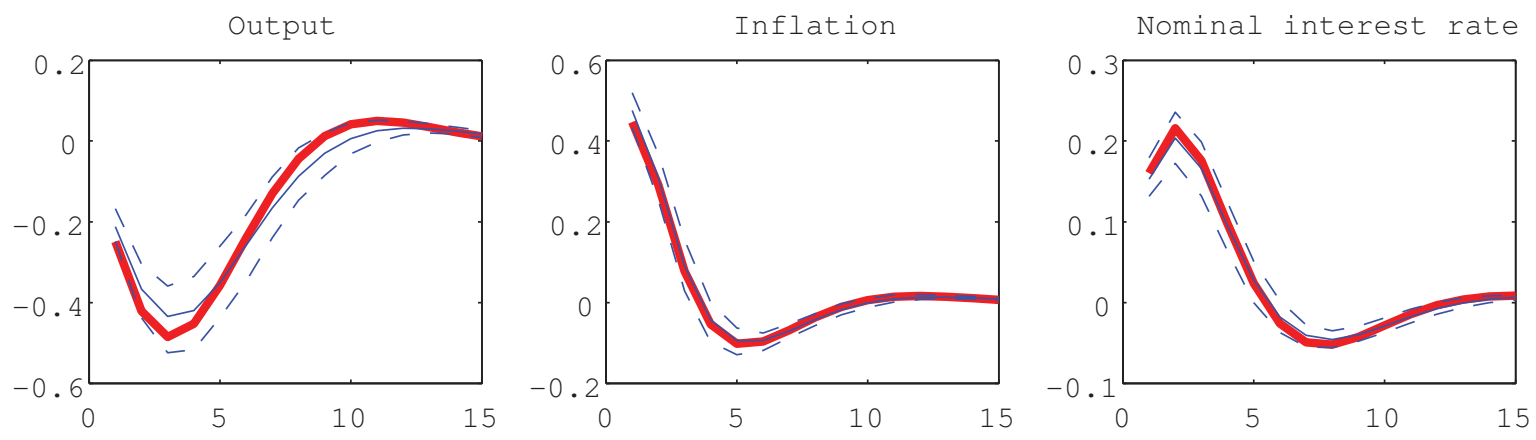

(7) Wage markup shock
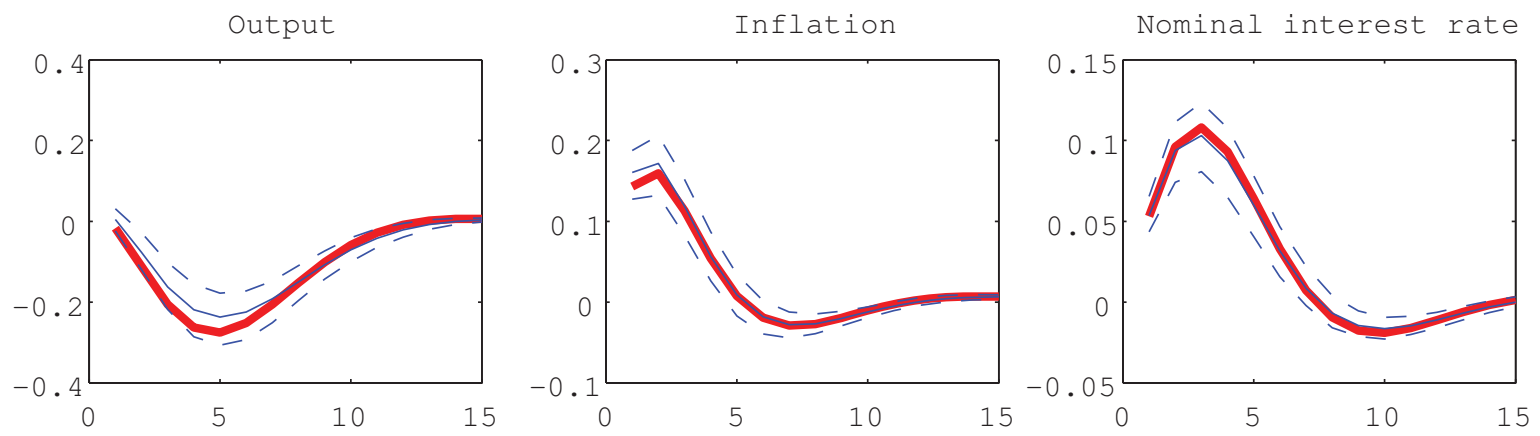

Notes: The figure shows the impulse responses of output, inflation, and the nominal interest rate (in terms of the percentage deviation from the steady state) to one standard deviation shocks in the TFP, the risk premium, external demand, investment, monetary policy, the price markup, and the wage markup. The solid thick lines represent the true responses, and the solid thin lines and dashed lines are respectively the posterior means and 90 percent credible intervals for the estimated responses. 